\title{
Liquidity and Efficiency in Three Related Foreign Exchange Options Markets
}

\author{
Menachem Brenner* and Ben Z. Schreiber ${ }^{* *}$
}

December 2006

\footnotetext{
* Stern School of Business, New York University. E-mail ; mbrenner@stern.nyu.edu

** Bank of Israel and Bar-Ilan University. E-mail ; schreibe@bankisrael.gov.il

We would like to thank David Afriat for technical assistance, Dror Shalit for providing the data from Tel Aviv Stock Exchange and Roi Stein and Rafi Eldor for helpful comments. We would like to thank the participants of the annual meeting of the Israeli Economic Association (2006) for helpful suggestions.
} 


\title{
Liquidity and Efficiency in Three Related Foreign Exchange Options Markets
}

\begin{abstract}
The foreign currency market in a small open economy, like Israel, plays a major role in fiscal and monetary policy decisions, through its effects on the financial markets and the real economy. In this paper we explore the liquidity and efficiency in three related foreign exchange options markets and the information content of the instruments traded in these markets. The unique data set on OTC trading and the central bank auctions, in addition to the exchange traded options provide us with insights about the operation of these markets, their relative efficiency, their information content and their interrelationship. An important aspect is the effect of liquidity on the pricing of options in these markets. As expected, we find that, except for extreme cases, liquidity does not affect options prices.
\end{abstract}

JEL Classification: F31, G13, G14

Keywords: Foreign Exchange, Implied Volatility, Liquidity, Bid-Ask Spread 


\section{INTRODUCTION}

In small open economies international trade plays a major role in the economic life of the country. It is an important part of GDP and contributes to the welfare of the economy. International transactions, involving goods and services or financial ones require exchange of currencies.

The rate at which one currency is exchanged for another depends not only on economic variables prevailing in both countries but also on the exchange rate policies in those countries including non transparent interventions by the authorities in both countries. Typically, a large country will not intervene in the currency exchange with a small one (e.g. Israel, Poland, Hong Kong). Thus, in a small open economy the exchange rate will depend on the exchange rate policy in that country in addition to the economic variables that determine the demand and supply of the currency.

In recent years, especially after the ' 97 Asian currency crisis, many small countries have abandoned the old restrictive policies in favor of less interventionist policies. Many have moved to a fully floating exchange rate though some of them have an unofficial intervention policy for cases when the currency moves outside a given range.

Since 1997 the Bank of Israel has not intervened directly in the currency market. Though it only recently (2005) abolished the official exchange rate band the currency movements were not restricted since the band was so wide ${ }^{1}$ that effectively it was ignored. Moreover, the currency markets have been totally liberalized ${ }^{2}$. Thus the exchange rates in recent years have been set in a free market environment. The volume of trading in spot dollar has increased substantially during the last decade and so did the trading in dollar derivatives; forwards and options.

Another recent development in many countries has been the use, by central banks ${ }^{3}$ of forward looking information derived from prices of traded instruments like CPI linked bonds, to obtain inflation expectations, or FX option prices, to obtain the distribution of FX rates. The Bank of Israel which has been using inflation expectations, derived from

\footnotetext{
${ }^{1}$ The width of the band during this period was almost $65 \%$.

2 Since July 1997 the Bank of Israel adopted a policy of non intervention in the FX market. This policy has not been changed even in turmoil periods such as the LTCM crisis in October 1998.

${ }^{3}$ The Bank of England is known to be using such information, in forming its monetary policy, for a number of years now.
} 
linked and non-linked bonds, for many years has recently added to its menu information derived from prices of FX options.

FX options in Israel are traded in three markets; the Tel-Aviv Stock Exchange (hereafter TASE), the banks' Over-The-Counter (hereafter OTC) market and the Bank Of Israel (hereafter BOI) auctions. Though the three markets trade essentially the same instruments the markets have different structures and different regulations which may result in differences in the information provided, in liquidity, in efficiency, etc. This raises the question, which is the relevant one? Should we pay attention to the more liquid market or to the more transparent market? Should we combine the information provided by all three markets? And, how spreads and implied volatilities are determined?

The objective of this study is three fold: First, to explore the efficiency of these related markets. Since the three markets trade the same instruments we can study the effect of different market structures on their efficiency and liquidity. Secondly, to examine the information content, its time series behavior, and its relevance. Third, what role does liquidity play in the price formation in these markets?

The next section of the paper provides a review of the relevant literature. Section III describes the FX market in Israel and the data. Section IV provides the methodology and the hypotheses. In section V we analyze the results, section VI provides an analysis of liquidity in these markets, section VII compares the forecasting ability of the future realized volatility of the three markets, and section VIII provides a summary and conclusions.

\section{REVIEW OF LITERATURE}

Though foreign exchange markets, spot and forward, are the largest global markets in the world, the research effort to study these markets has been relatively modest compared to the research on equities markets or the fixed income markets. It is especially so for research on FX options markets. Moreover, research which focuses on the role that options markets play in policy decisions made by central banks is even scantier.

Next we will briefly describe the main findings regarding FX options in general and then discuss the papers which deal with the use of FX options by central banks. 
It is first important to mention some general studies, not option based, which have looked at realized volatility in order to learn about the dynamics of the underlying asset, namely FX rates. One such study, by Andersen et al. (2001), using high frequency data on DM/\$ and Yen $/ \$$ find high correlation across volatilities, persistent dynamics in volatilities and correlation and long memory dynamics in volatilities and correlation.

Using options on currency futures trading on the Chicago Mercantile Exchange, Jorion (1995) finds that implied volatility, though biased, is a better predictor of future volatility than other time-series models. This finding is corroborated by a later study of Szakmary et al. (2003) on 35 futures markets which include 5 currency futures. For the FX options in their study, they find that IV is a better predictor of Realized volatility than Historical volatility. These papers use daily data and use Black's model (1976) to compute implied volatility. In a more recent paper Pong et al. (2004) use high frequency data and four methods for forecasting currency volatility. They find that intraday exchange rates provide more accurate forecasts for short horizon volatilities, up to a week, while for longer horizons, one and three months, implied volatilities are at least as accurate as the intraday data. A study by Campa and Chang (1995) explores the term structure of currencies' volatility and finds that short term volatilities are more variable than long term ones which highlights the issue of stochastic volatility in currencies. A couple of recent studies have examined the stochastic nature of volatility. Low and Zhang (2005) use currency options traded in the OTC market to study whether volatility risk is being priced in the options. Using at-the-money straddles they find that volatility risk premium is negative and it decreases with maturity. The above studies have essentially used near the money options or averages of implied volatilities across strikes. Bollen, Gray and Whaley (2000) use currency options to determine whether market prices reflect a regime switching behavior of the currency market as their model suggests. They find that option prices do not fully reflect the regime switching information. Duan and Wei (1999) use a GARCH option pricing methodology to value FX options. Their results show that their model can explain the stylized facts observed in the FX market like, for example, "fat tails". The dynamics of implied volatility in the FX market are also studied by Kim (2003) who finds that current large fluctuations in the currency market have a significant effect on expected future volatility as exhibited by implied volatility. It is also claimed that traders' private information affects implied volatility in the short run. A study by Carr 
and $\mathrm{Wu}$ (2004) examines the implied return distribution of FX rates. They use OTC option quotes on two active currencies; the yen $/ \$$ and the $\mathrm{BP} / \$$. They analyze the behavior of option implied volatility across moneyness, maturity, and calendar time. They find that it is symmetrically higher in the tails (a "smile") and persistent over long maturities and calendar time. The symmetry, the "smile", phenomenon in currency options could be simply explained by the fact that either tail represents the strength of one currency and the weakness of the other one. A "leverage" type argument where a decline in the basic asset triggers an increase in volatility would apply equally to both, the out-of-the-money puts and the out-of- the-money calls.

Liquidity is found to substantially affect prices in many asset classes and markets (see Amihud and Mendelson, 2006). The effect of liquidity on the pricing of FX options is examined by Brenner, Eldor and Hauser (2001). Though, as pointed out in their paper, illiquidity should not affect the prices of derivatives, they find that the illiquid BOI options have traded at a $20 \%$ discount. This is explained by the fact that the writer, the central bank, does not demand a liquidity premium while the buyers do. In a similar study on the non-tradability of Treasury derivatives in the Israeli market Eldor, Hauser, Kahn and Kamara (2006) find that the non-tradables had a premium of 38 basis points. Another recent paper by Eldor, Hauser, Pilo and Shurki (2006) finds that the introduction of market makers in ILS/EUR options, traded at TASE, increased volumes and decreased the bid ask spreads. This paper is relevant as ILS/USD options which are included in our study and traded at TASE without a designated market maker while those ILS/USD options traded in the OTC market are dominated by large commercial banks which provide two sided quotes and effectively act as market makers.

In general, most studies use currencies of large and developed economies; the U.S., Japan, Britain, Europe. Also, some of these studies use exchange traded prices (e.g. The Philadelphia Stock Exchange or The Chicago Mercantile Exchange) while others use OTC transactions data. The tradeoff here is between the small volume of transparent exchange transactions and not as transparent OTC trading which is where almost all FX trading is done. Thus, the lessons from these studies may not be applicable to the many smaller but open economies. In fact, in such countries the information obtained from such markets could play even a bigger role in policy decisions by the government and/or the central bank. Since most of these currency markets were, until recently, controlled or 
managed by the government or the central bank the information content was rather limited. Also, most of the trading was done in the OTC banking system and data was not easily available, in particular data on options trading ${ }^{4}$.

In our study, however, we had access, not only to the exchange traded data but also to the OTC-banks' data. We use data from three different markets where only one of them, the TASE, is completely transparent. The data of the other two, however, is reliable since it is reported by the central bank, the BOI auction data, and the OTC data is reported by each bank to the central bank as required by law. This is the most comprehensive data on ILS/USD transactions available as it is gathered from all markets that trade these options in Israel. ${ }^{5}$

\section{THE FX MARKET AND THE DATA}

\section{The FX market in Israel}

The currency market in Israel was essentially a free market during the sample period but most transactions in the spot market are done through the banking system. The US dollar is the most traded currency (second comes the Euro) by corporations, financial institutions and individuals. Trading in spot and forwards is done OTC, through and by, the banks. Trading in futures and options is done on the TASE and in the OTC market. Some options are issued by the central bank (BOI) in an auction, twice a week.

Trading in currency options on the TASE has commenced in 1994 and its volume has increased steadily until 2001 where our sample period begins. The options trade in a continuous electronic market.

\section{[Insert Figure 1 here]}

During the first half of 2002, after the unexpected cut of interest rate and the 'Palestinian Intifada', the volumes increased dramatically but later they returned to the pre 2002 levels. Since the inception of trading on the exchange the banks have been offering their

\footnotetext{
${ }^{4}$ The trading in derivatives by the banks is tailor made and may include exotic features. In the case of options the bank will typically be the writer.

${ }^{5}$ To the best of our knowledge these FX options did not trade in any other market outside of Israel during the sample period.
} 
customers a variety of FX options, plain vanilla and exotic ones. The third source of FX options is the BOI. Since 1993, the BOI has been offering At-The-Money-Forward (ATMF; $\mathrm{X}=\mathrm{Se}^{\left(\mathrm{r}-\mathrm{r}^{*}\right) \mathrm{t}}$, see Table 2 for definitions of the terms), put and call options for three and six months, respectively. These are offered in an auction twice a week and do not trade until expiration.

\section{Description of the data}

In this study we use data from these three distinct but related markets. Our sample consists of call and put options on the US dollar (USD), paid in the New Israeli Shekel (ILS) for the period October 2001 to December 2004. Data is collected, on a weekly basis, from the local banks for OTC options, from the Tel-Aviv Stock Exchange for TASE options, and from the Bank of Israel for BOI options. The collected data covers all transactions of ILS/USD options in Israel ${ }^{6}$ and, to the best of our knowledge it is the most comprehensive data set available ${ }^{7}$. No other study has used all three sources of data, in particular the OTC data, and had the same objectives as ours. The study by Brenner, Eldor, and Hauser (BEH) (2001) focused on the effect of liquidity on the auctioned BOI options by comparing them to the options that trade on the TASE. Also, our study uses current data, a period free of constraints on currency trading. The data consists of prices, volumes and open interest. All options, including the banks' OTC options, are plain vanilla European type options. They differ by their strike prices and maturities. They all are cash settled using the so called "representative" exchange rate published by the Bank of Israel during afternoon hours each trading day ${ }^{8}$. We use the LIBOR (London Interbank Borrowing Offered Rate) and the short term Makam (the domestic equivalent of LIBOR, issued by the BOI) rates as the foreign and domestic interest rates, respectively.

\footnotetext{
${ }^{6}$ Since July 1997 the BOI is not intervening in the currency market and in 2004 the final step in the liberalization of the currency market has been implemented.

${ }^{7}$ Since the banks are obliged to report all their transactions to the BOI we assume that our data is the most comprehensive available.

${ }^{8}$ The representative rate is calculated by sampling the exchange rate prevailed among local banks between 14:15 and 15:15 on Monday thru Thursday and between 12:15 and 13:15 on Friday. Using closing prices or the mean of the daily exchange rates has not affected the results in any meaningful way. See Appendix 1 for details.
} 
We start with the computation of implied volatility ${ }^{9}$ (IV) to filter outliers that may either bias the results and/or may introduce noise that has very little to do with the normal conduct of the market. First, we exclude from the sample observations with missing values such as days to expiration or striking price. Secondly, we exclude from the sample outliers by defining the following a-parametric filter regarding implied volatility: $\left[Q_{1}-\right.$ $\left.3 \cdot\left(Q_{3}-Q_{1}\right)\right] \div\left[Q_{3}+3 \cdot\left(Q_{3}-Q_{1}\right)\right]$ where $Q_{j}$ is the $j$ th quartile $\{j=1 . .4\}^{10}$. As a result of the exclusion, the number of transactions in our sample was reduced by 4 percent and amounted to 34,529 in OTC, 21,182 traded in TASE, and 315 in BOI daily auctions ${ }^{11}$.

[Insert Tables 1 and 2 here]

Table 1 provides a glimpse of the differences in several aspects between these markets. The upper panel provides a qualitative comparison of basic features of these markets. For example, it depicts the type of players in each market and the spectrum of derivative instruments. The lower panel of Table 1 provides some numbers regarding volume, open interest and size of an average trade. The BOI market is relatively small compared to the other two markets. The main idea behind the central bank involvement, writing FX options, was to provide a vehicle to hedge FX risk when such a market did not exist and provide a benchmark that will help create such a market. The notional volume offered in the auctions was always limited. On the other hand, the size of the other two markets is in principle unlimited and indeed over the years they grew rapidly. The average volume of TASE is much higher than that of the OTC ( 8.1 billion USD per month versus 4.6 billion) while, open interests, notional values per transaction and accordingly actual premiums of OTC options are higher than those of TASE ${ }^{12}$. These differences reflect the various characteristics of TASE and OTC markets. In Particular, time to expiration is longer on

\footnotetext{
9 As all options are European plain vanilla, IV derived from option prices traded on the three markets is calculated in the same way. However, there is one substantial difference due to data limitations; the daily IV of OTC market is derived from all transactions during the trading day while those of TASE and BOI are based on closing prices.

${ }^{10}$ As a result the biggest IV is approximately $25 \%$ and the smallest is $1 \%$. A different filter which includes only transactions whose implied volatility is within the range of $\mu \pm 2 \sigma$ has not changed the results, significantly.

${ }^{11}$ Each BOI auction is for a mean notional of approximately 20 million US dollars (puts and calls for 3 and 6 months maturities).

${ }^{12}$ By the Bank of International Settlement (2003), the annual turnover of currency options that are traded on organized exchanges was about USD1.3 trillion in 1995 and declined to USD0.36 trillion in 2001. In contrast, the annual turnover on the OTC markets was about USD10.25 trillion in 1995 and about USD15 trillion in 2001.
} 
the OTC and moneyness ${ }^{13}$ is more negative (i.e., more Out-of-The-Money-Forward OTMF) in that market (see Table 2). These differences are reflected in the various implied volatilities (IV): the highest IV is on the TASE which is characterized by many small transactions while the lowest IV is derived from the BOI options where actually only banks are participating in this market and it is characterized by a few large transactions (an auction twice a week). Later we discuss this phenomenon in more detail. In Table 2 we present basic statistics of these markets regarding volumes, implied volatilities, moneyness, and time to expiration. The BOI options are only calls and puts with a 3 month maturity however, we did not restrict, in Table 2, the moneyness of the other two markets to just ATMF options, as are the BOI options.

The results of the comparison of the 3 markets exhibit the importance of the so-called 'implied volatility surface' (combinations of time to expiration and moneyness with regard to IV $)^{14}$. The highest average implied volatility, $9.1 \%$, is obtained from options traded on the TASE, the OTC options imply a volatility of $7.9 \%$ while the BOI options have an implied of $6.7 \%$. These differences can be explained by various transactions costs due to differences in; transactions size, time to expiration and moneyness. Illiquidity, in general, could not explain differences in IVs in efficient derivatives markets, as explained in Brenner et al. (2001) except for a case where one side is the writer like the central bank. Even then the difference should be up to transactions costs. This may explain the lower IV for the BOI options but we have no reason to believe, $a$ priori, that illiquidity can explain the difference between the prices on the TASE and those set in the OTC market unless the markets are inefficient or there is a dominant player e.g., the banks in the OTC market. An important factor explaining the lower IV for ATMF BOI options vis-à-vis the OTC and TASE is the "smile" effect which will make the weighted average IV for the OTC and the TASE higher. The two markets here, the TASE and, to some extent, the OTC exhibit a "smile" which is also been found in most currency markets (see for example, Carr and $\mathrm{Wu}$ (2004)). Time to expiration is expected

${ }^{13}$ Defined in this paper as $M_{C}=\operatorname{Ln}\left(\frac{S e^{-r^{*} t}}{X e^{-r t}}\right)$ for call options and $M_{P}=\operatorname{Ln}\left(\frac{X e^{-r t}}{S e^{-r^{*} t}}\right)$ for put options where, $\mathrm{S}$ is the spot rate, $\mathrm{X}$ is the striking price, $\mathrm{r}$ and $\mathrm{r}^{*}$ are local and foreign interest rate, respectively, and $\mathrm{t}$ is time to expiration in annual terms.

${ }^{14}$ Goncalves and Guidolin (2005) also find that the surface derived from the S\&P500 is important in constructing profitable strategies. Thus, arbitrage opportunities can emerge in the surface edges rather in the center, options that are away from the money rather than at-the-money. 
to partially offset the former effect. These overall observations will be later contrasted with observations derived from options with comparable strikes and maturities.

As robustness tests we have used some alternative exchange rates (see Appendix 1) and call options vs. put options (Table 3). It appears that the results are not sensitive to either the somewhat different underlying exchange rates that we use or to the type of option, call vs. put.

[Insert Table 3 here]

In both markets, however, we find that the mean of implied volatilities derived from call options is higher than that of put options which is a violation of put-call parity (the options are European).

Another interesting observation is that the ratio of call to put transactions in TASE is larger than the respective figure regarding the OTC. The difference in the call/put ratio could be explained by the dominance of retail customers on the TASE who are using options either to speculate or hedge their risk against depreciation in the ILS/USD exchange rate. Also, the moneyness of the calls is less Out-of-The-Money-Forward (OTMF) than puts while days to maturity of calls are longer.

\section{METHODOLOGY, HYPOTHESES, AND TESTS The spot FX market}

In Table 4 we present some basic statistics of the changes $\left(\log \left(\mathrm{S}_{\mathrm{t}} / \mathrm{S}_{\mathrm{t}-1}\right)\right)$ in the ILS/USD exchange rate. Although the Jarque-Bera test strictly rejects the hypothesis of a normal distribution, the rejection is due to deviations around the mean rather than "fat tails" and it seems to be symmetric. We next examine the volatility of the exchange rate over the period of the study, 10/2001-12/2004, using three alternative models of the GARCH family.

[Insert Table 4 here]

As observed for other exchange rates, we first used a GARCH $(1,1)$ which treats the errors symmetrically. Yesterday's variance has the strongest effect on the subsequent day which is evidence of persistence. This evidence is consistent with the high 
autocorrelation exhibited by the time series of IVs. The error term (shock or news at day t-1) does not have a significant effect on the current variance compared to the variance of yesterday which is an indication that the typical error term is small and its effect fades away quickly. The second and the third models are the Threshold GARCH (see Glosten et al., 1993) and Exponential GARCH which split the errors in two, positive and negative, to examine the possibility of asymmetric effects on the variance. It turns out that the inclusion of a positive/negative dummy is justified as the coefficient turns out to be significant. Thus, a positive shock to the ILS/USD exchange rate occurred in day t-1 influences the latter volatility of day $t$ more than a negative shock. It should be noted that a negative economic shock in a small open economy would usually show up in a large devaluation of the currency with respect to the major currencies and that will be associated with a rise in the volatility of the exchange rate. Interestingly, as we show later this apparent asymmetric behavior will not show up in the behavior of the IVs.

\section{The Similarity of the Three FX Option Markets}

In the first set of tests we try to answer the following question: is the information content as measured by implied volatility and more directly by the option premium the same in all three markets? If it is different, what are the factors that explain the difference? Alternatively, is there room for arbitrage between the markets?

Thus, our null hypothesis is that the three markets are integrated and any difference should be explainable by transactions costs. The null hypothesis regarding any pair of markets e.g., BOI vs. TASE, BOI vs. OTC, and TASE vs. OTC, is tested by two methods:

1. Comparing implied volatilities (IV) computed from similar options.

2. Comparing option prices using the methodology outlined in Brenner, et al. (2001).

The IV is computed using the Black-Scholes-Merton (BSM) model adjusted for FX options (Garman-Kohlhagen, (1983)). All options in our study are European type and are cash settled. Though, in general, empirical observations are not consistent with model predictions due possibly to stochastic volatility or/and jumps, the model performs relatively well when applied to FX options (see for example, Jorion, 1995). In fact, the common practice in the global FX market is to quote and trade in IVs, especially ATMF 
options. Moreover, we have no reason to believe that the presence of stochastic volatility, for example, should induce a bias in comparing the three option markets which relate to the same underlying asset.

Our first test uses the IVs of basically ATMF options. Since our task here is to compare options markets on the same underlying we can use the same price transformation as long as the options do not have very different specifications.

\section{HYPOTHESES AND RESULTS}

We first present the hypotheses and results by comparing the distributions of IV across the 3 markets. The null hypothesis $\mathrm{H}_{0}$ : IV $(\mathrm{BOI})=\operatorname{IV}(\mathrm{TASE}) ; \operatorname{IV}(\mathrm{BOI})=$ $\operatorname{IV}(\mathrm{OTC}) ; \mathrm{IV}(\mathrm{TASE})=\mathrm{IV}(\mathrm{OTC})$, is tested using several parametric and non-parametric tests. In Table 5 we summarize the results in words since the alternative tests give us similar answers as to their significance. In other words, the results are robust vis-à-vis the tests we employ.

[Insert Table 5 here]

We first test the differences in mean, median and variance between the BOI and OTC and between the BOI and TASE. Since the BOI options are always ATMF and issued with 3 month to maturity we try to match, as closely as possible, the OTC and TASE options to the BOI terms. As reported in Table 5, top panel on the left, we could not reject, at the $5 \%$ level, the null hypothesis that the implied volatility of the OTC or TASE is the same as the one derived from the BOI options. This contradicts the IV results that were reported by Brenner et al. (2001) for BOI options vs. TASE options in an earlier period. However, it is consistent with the results in their last period when the markets matured and became more efficient.

In testing the OTC vs. the TASE we used all options across strikes (ITMF, ATMF, and OTMF) and maturities and the results were, by and large, different. The hypothesis of equal mean, median, and variance was rejected for OTMF and ITMF options while for ATMF options, only the equal mean hypothesis was rejected. A similar picture is revealed by looking at Figures 2 and 3 . 
[Insert Figures 2 and 3]

Figure 2 depicts the IVs derived from all data (excluding the outliers, as described in the data section) while Figure 3 uses comparable data only. Using all the data the IVs derived from TASE options are the highest, as observed in Figure 2 and Table 2, while those of BOI are the lowest. These differences largely disappear when comparable data is used, as can be observed in Figure 3. The average IV in the three markets; BOI, OTC, TASE, are indistinguishable from each other $(7.2 \%, 7.5 \%$, and $7.5 \%$, respectively).

These results lead us to look for the source of the differences between the results that use all available data and the results that use only common data. Is the difference all in the tails? Does it all result from OTMF/ITMF options? Are the differences in the tails a result of "fat tails' in the underlying asset or due to transactions costs and/or relative liquidity? Though we could not reject the hypothesis of the same information content using the mean of IVs as our statistic we were mainly interested in finding out whether the differences in liquidity in these markets is the source of the difference in IVs (prices). The BOI is at one extreme where, after the auction, the options do not trade until maturity. The TASE options are on the other end, where the same options trade or, could trade, all the time until maturity. The OTC options are in between where similar, not the same, options could be issued any day but usually the position is not offset by trading. Though these differences in liquidity do exist, it might not show up in price differences, or IV differences, in efficient markets for two reasons: As explained above, and in Brenner et al. (2001), derivative assets should not command a liquidity premium or a discount since they are a zero-sum game. Moreover, in any efficient derivative markets potential arbitrage, in particular across option markets on the same underlying asset, should eliminate price differences between the markets up to transactions costs. In contrast, price differences can prevail if there are liquidity problems i.e., if there is not enough supply/demand to carry out the arbitrage.

In the upper panel of Table 5 we present the results of a test that uses the difference in the prices of options to test for differences between these markets (based on the methodology in Brenner et al. (2001)). The price difference, also termed the liquidity 
premium, of OTC versus TASE depends on moneyness .While the average price of TASE options using all options is larger than OTC ones by $3.1 \%$, the average price of OTMF TASE options is larger than that of OTC by $8.3 \%$. In contrast, the mean price of ATMF TASE options is smaller than that of OTC by $4.6 \%$ and for ITMF options there is almost no difference. These results are also shown in Figure 4.

\section{[Insert Figure 4 here]}

On the upper left side of the figure i.e., the $1^{\text {st }}$ quintile of the distribution of both moneyness and 'time to expiration', TASE options are more expensive than OTC options. In the $3^{\text {rd }}$ quintile this is reversed, the TASE options are less expensive. Thus the differences in IV (or, in prices) do not coincide with differences in liquidity which supports our argument that in derivative markets illiquidity should not be a pricing factor as it is in the underlying asset markets once the markets are efficient. We thus should be looking for another explanation for the differences we observe in the moneymess domain. One possible explanation could be that the banks are mainly the writers of OTMF options and the customers will be locked in their position unless they create an identical offsetting position on the TASE or on the OTC which they will carry to maturity which amounts to a non-tradeability discount that is very costly to arbitrage. The opposite may be true for ATMF options where the banks could be mainly on the buying $\operatorname{side}^{15}$. To verify this conjecture we would need detailed data on option customers' positions which are currently unavailable. Another angle would be to examine the measurable transactions costs that an arbitrageur would incur assuming that the banks are not the dominant players on either side, long or short. Could transactions costs associated with arbitraging the OTMF OTC options with the ATMF wipe out the differences in prices since it will require dynamic hedging?

Concerning the three markets, the pair wise comparison of comparable daily data, bottom panel of Table 5, shows that, on average the BOI options have a discount of about $2.9 \%$ vis-à-vis OTC and $2.5 \%$ vis-à-vis TASE. Although it is statistically significant, to arbitrage these differences will cost more than 3\% whether the other market is the OTC or the TASE. It should be noted that we used the same methodology used in Brenner et

${ }^{15}$ A similar argument is made in a recent paper by Deuskar et al. (2006). 
al. (2001) and the results for BOI vs. TASE are drastically different, where the discount in the last period of the study, 1996-97, amounted to $15 \%$ before transactions costs. Apparently, it has taken the markets 4 years to reduce this discount to the current transaction costs levels.

The other interesting comparison is between the OTC options market and the TASE. Though the options issued by the banks in the OTC market are essentially bi-lateral, tailor made agreements, and as such do not trade until maturity, we found that the same options, using the above matching methodology, by strike price and maturity, have essentially the same prices; the mean difference is $1.4 \%$ which is lower than transactions costs in these markets. Hence, arbitrage activity between these markets is probably not profitable except for deep Out-of-The-Money-Forward (OTMF) short term options. This exception, which was also found by Low and Zhang (2005) may reflect a volatility risk premium and/or the dominance of Banks on one side of the trade, long or short.

\section{OTC versus TASE: A closer look}

Though the options issued by the BOI are used as a benchmark, the lessons from this market are limited since they are limited in size, frequency, strike prices and maturities. The two sizable markets which trade similar instruments but have very different market structures are TASE and OTC. We hope that what we learn here will help us understand other similar markets. In essence we have an electronic options market in FX which trades continuously and concurrently with the spot market and an OTC market which offers the same kind of options, long or short, but these options do not trade in a secondary market. Potentially one can reverse his position by entering a new contract with the same terms or offsetting his position with the bank's consent. Given our unique data set that includes essentially all contracts made in the OTC during $10 / 2001$ and 12/2004 we can learn about how the two markets compete and/or complement each other. We are especially interested in the micro structure differences in the two markets and how they affect trading in these markets. Figures $5 \mathrm{a}$ and $5 \mathrm{~b}$ present the surface (IV along moneyness and 'time to expiration' quintiles) of OTC and TASE, respectively. 
[Insert Figures 5a and 5b here]

As one can see the main differences between the two surfaces are in the edges. Particularly, short term OTMF TASE options (quintile 1 in both dimensions) are more expensive compared to the respective OTC options while the opposite holds for ITMF options. The TASE options surface exhibits more of a 'smile type' surface while the OTC surface seems more flat with a slight 'skew'.

\section{LIQUIDITY AND TRANSACTIONS COSTS}

Though these markets are strongly related they differ by their structure, liquidity being an important feature, and by their players. In this section we would like to focus on micro-structure issues and how they may be affecting the integration and efficiency of these markets. Since the BOI options are sold twice a week in an auction in limited quantities and have minimal transactions costs associated with them ${ }^{16}$, we will focus our attention on the two main markets, the OTC and TASE.

In Table 6 we provide information on the bid-ask (B-A) spread, usually the main component of transactions costs, in these two markets.

[Insert Table 6 here]

First, the mean proportionate B-A spread (the B-A spread divided by the average B-A) across all option series on the TASE is about $17.5 \%$ while on the OTC market it is about $9.5 \%$. This difference can be explained by the differences in trading in the two markets. The main difference between the two markets is in the way that these markets trade. In the OTC, one can get a firm quote from a bank any time during the trading day, while on the TASE the B-A spread is provided by the buy and sell limit orders that continuously arrive at the market. Since there is no market maker who is willing to quote both sides all the time we may have wider spreads in the less liquid options, the OTMF which are far

\footnotetext{
${ }^{16}$ As discussed before, the BOI options are issued by the central bank and do not trade until maturity. The effect of this non tradability (illiquidity) has been investigated in Brenner et al. (2001) on an earlier period. Here we reexamine it in relation to the TASE and to the OTC.
} 
out. This argument is consistent with Eldor et al. (2006) who find smaller B-A spreads in the ILS/EUR options traded on the TASE after market makers had started to operate. Also, it should be noted that the quoted/displayed B-A spreads only measure the cost of a given trading volume and does not tell us about the cost generated by a bigger order, the so called 'price impact'.

When we examine the more liquid options series here, the OTMF we find that in both markets the spreads are lower than in the ATMF and ITMF options. Moreover, the differences between the two markets are much smaller, $2.7 \%$ for OTMF options $(13.9 \%$ on the TASE vs. $11.2 \%$ on the OTC) and $4.9 \%$ for ATMF options (18.1\% vs. $13.2 \%)$. The variance of the B-A spread across all options is also smaller in the OTC market which again may be explained by the 'market making' position that the banks effectively assume.

An important factor affecting the B-A spread of a basic asset is the volatility of the asset. Here, however, we are dealing with the B-A spread in the options market and its relationship to the volatility of the underlying asset. These we believe can be related arguably by a hedging argument where the volatility of the underlying affects the B-A spread of the underlying which affects the B-A spread of the option since the option can be replicated by the underlying and vice versa. On the other hand, if we use IV to represent expected volatility, under B-S-M, a higher IV should result in a higher B-A spread and vice versa. A higher B-A spread which reflects also less liquidity, of the combined markets, may result in higher volatility. Thus, our hypothesis is that both IV and B-A spreads are determined simultaneously and have a positive impact on each other. This hypothesis is in contrast with the current practice to regressing B-A spreads on volatility. We are testing the B-A spreads relationship to IV in TASE and OTC using Three Stage Least Squares (3SLS) Regressions.

[Insert Table 7 here]

To minimize the effects of serial correlation that characterizes both series and avoiding different levels of integrations, we have applied the 3SLS to the first differences of daily IV and B-A spreads ${ }^{17}$. The upper panels of Table 7 (panels (a) and (b)) depict the results

17 The differences are all $\mathrm{I}(0)$. 
of OLS regressions where IV and B-A spreads are regressed on moneyness, days to expiration, and size. In both markets B-A spreads and IV positively influence one each other as expected. Size measured in the regressions as the options' notional values is positively (although not significant) affecting the IVs while its impact on B-A spreads is not unequivocal. Size should negatively influence B-A spreads while the positive relationship with IV can be explained by the turbulent periods, reflected in high levels of IV, which are characterized by more transactions and volumes in the option markets. Days to expiration may have a negative effect on IV due to mean reversion and/or volatility risk premium as in Campa and Chang (1995) and Low and Zhang (2005). The impact of moneyness on IVs is positive and robust for TASE while negative and less significant for OTC. This is associated with the shapes of the respective surfaces (figures $5 \mathrm{a}$ and $5 \mathrm{~b}$ ): the "smile" phenomenon is observed only in the TASE while the shape of the OTC surface is more flat and slightly 'skewed'. Finally, in both markets the endogenous variables are highly autoregressive - a phenomenon also found in other studies (see Granger and Poon, 2003).

In the lower panel of Table 7, IV and B-A spreads are regressed simultaneously on the above exogenous variables using 3SLS. In almost all cases the results are the same either in the direction of the impact or the level of robustness. Our main conjecture concerning the interrelations between IV and B-A spreads in the FX market, to the best of our knowledge, has not been reported before.

We also examined the differences between the OTC and TASE markets regarding their market depth and efficiency. Following Eldor et al. (2006) who examined the efficiency and depth of the ILS/EUR options market traded on the TASE, we use the so called "Amihud measure" (see Amihud, 2002), the change in price associated with volume changes as a measure of depth, the IV surface (by measuring its skewness) and the deviations from put-call-parity. In all of the above measures, figures closer to zero reflect more efficient and deeper markets.

[Insert Table 8 here]

It can be seen that in most cases the figures for the TASE are smaller. I.e., it is more liquid and more efficient than the OTC market. This is reasonable as the TASE market is 
more transparent and accessible to the public. Market depth of the TASE, calculated as the ratio of the percentage change of option prices relative to the volume, in each trading day, is larger than in the OTC in all moneyness categories. For example, the OTC figure is 6 basis points (hereafter bp) compared to $2.9 \mathrm{bp}$ in TASE's ILS/USD options and 2.8 bp in TASE's ILS/EUR options (see Eldor et al. (2006)).

The second comparison looks at the IV surface by estimating its skewness. These deviations from Black and Scholes (1973) assumptions (the 'smile' or 'smirk' effect) may be related to a decreased liquidity and/or higher transaction costs. The skewness of both markets was negative while that of OTC was almost 6 times larger (in absolute values) than that of TASE. The respective figure regarding TASE's ILS/EUR options reported in Eldor et al. (2006) is between the OTC and TASE ILS/USD options.

The third comparison looks at the deviations from put-call-parity, which could provide arbitrage opportunities, in both markets. The deviations are smaller in the TASE across all moneyness categories compared to the OTC. For example, the deviations across all transactions was $-3.4 \mathrm{bp}$ in OTC compared to $-0.5 \mathrm{bp}$ in TASE and approximately $-16 \mathrm{bp}$ in TASE's ILS/EUR options as reported in Eldor et al. $(2006)^{18}$.

To summarize these findings, although the B-A spread, a measure of liquidity, is smaller on the OTC than on the TASE, the latter seems to provide greater depth than the OTC, especially in the options which are ATMF or slightly OTMF. This difference probably reflects the differences in the micro structure of these markets. Thus, while the prices, as reflected in their IVs, are the same as a result of arbitragers operating in both markets, the B-A spreads of TASE are larger than those of the OTC due to the fact that the TASE is a pure electronic market with no designated market makers while in the OTC the banks effectively act as 'market makers'. However, when it comes to options that trade frequently in bigger quantities the electronic market making becomes less important. The effective market making activity can also explain the differences in the

\footnotetext{
18 The substantial differences between this study and that of Eldor et al. (2006) can be explained by the differences in averaging. Eldor et al. (2006) calculate the deviations from put-call-parity, transaction by transaction and then average all deviations. Instead, we calculate the deviation of every single trading day using single spot rate, single local, and single foreign interest rate, then we average over all trading days. Thus, our results are less robust although the differences between the OTC and TASE are consistent with the other measures and with our conjectures.
} 
volatility surfaces in these markets. The apparent relative deviations from put-call parity in the OTC market may not reflect arbitrage opportunities since it is not transparent and continuous as is the TASE.

\section{FORECASTING ABILITY OF ILS/USD FUTURE VOLATILITY}

Information content of options can be examined in several ways. One such examination is to look at the forecasting ability of option prices vis-à-vis the future volatility of FX spot. Figure 6 presents the IV derived from BOI options, future realized volatility, and a VIX (using the volatility index methodology) measure applied to the ILS/USD exchange rate.

\section{[Insert Figure 6 here]}

In order to avoid overlapping in the forecasts, we derive the various IVs for the next quarter using 3 months options traded at the first week of each quarter. The Figure shows that the various IVs are higher almost in all the sample period than the future realized volatility within the next quarter. However, the correlations among all IVs and between them and the future realized volatility are relatively high (see the lower panel of Figure 6). Since we have three options markets operating concurrently we would like to know whether they have the same ability to forecast the future realized volatility. We compute implied volatility from all options as well as ATMF options only, in all three markets. The realized future volatility (RV) for the next quarter is computed using daily returns of ILS/USD in each quarter except the first week. The IV of all three markets is highly correlated with RV, about 0.8 while the correlation coefficient among the IV of the three markets is higher - around 0.97 . We test the forecasting ability of the three markets by using two tests: Mean Errors (ME) and Root Mean Square Errors (RMSE). The former reflects the direction of the error biasness while the latter reflects the accuracy of forecasting. In general, all forecasts overestimated the true volatility as in Christiensen and Prabhala (1998) and Szakmary et al. (2003). However, forecasts derived from ATMF options outperformed forecasts based on all options. In addition, among the three markets, BOI and OTC ATMF were the best forecasters although all three markets were 
close in their forecasting ability. These results support further the evidence that the three markets function rather efficiently, are closely related and arbitrage activity may not be a profitable activity.

The interrelations between the three markets are prominently shown around the days of expiration at the TASE.

[Insert Table 9 here]

The table presents volumes and number of transactions of the three markets across the days of the month. While the differences between these days are random the days around the expiration at TASE are characterized by very high volumes and number of transactions in all markets. For example, the volume in an average day in OTC and BOI are $41 \%$ and $27 \%$, respectively that of the expiration day. In contrast, a day before TASE's expiration the figures go up to $61 \%$ and $94 \%$, respectively and a day after expiration these figures jump to $92 \%$ and $86 \%$, respectively. These phenomena reflect both the 'roll over' of the expiring options to the new ones and the interrelationships among the three markets where large volume in TASE is related to large volumes in the other markets.

\section{SUMMARY AND CONCLUSIONS}

This paper explores the efficiency of three related FX (ILS/USD) options markets, the effect of liquidity and the information content of the instruments traded in them in the period 10/2001-12/2004. The unique data sets on the three markets: Tel Aviv Stock Exchange (TASE), Over The Counter (OTC) and Bank Of Israel (BOI), provide us with insights about the operation of these markets, their relative efficiency, their relative liquidity, their information content and their interrelationship. Specifically, we compare the implied volatility (IV) surface, liquidity measures such as the bid-ask (B-A) spread, market depth and the forecasting ability of these markets controlling for moneyness, time to expiration, and other explanatory variables. We find that the differences between the 
markets as reflected in their IV or B-A surfaces is not large (across moneyness and time to expiration). Moreover, although the IV surface in TASE is a 'smile type' and that of OTC is flat with a slight 'skew' there is no arbitrage opportunity. What seems to be an arbitrage opportunity, in the very short term far OTMF options, is probably wiped out by transactions costs. For these options the B-A spread is the widest and the volumes are the smallest. It is also found that IV and B-A spreads are simultaneously determined, have a positive affect on each other and mainly influenced by the shape of the IV function rather then time to expiration, size, or other explanatory variables examined. These findings apply more to the TASE and less to the OTC market - perhaps due to the above differences in shapes. In general, B-A spreads in TASE are wider than in OTC possibly due to the dominant position of local banks who act as market makers in the OTC FX option market. In contrast, market depth and efficiency measures that were larger in TASE than in OTC offset the B-A spreads of the former. This unique data set provides us with an insight on the relative importance of the various factors affecting options prices, in particular the non role of liquidity, in contrast to the underlying assets market.

Comparing the forecasting ability of future volatility by the current IV during the sample period shows that forecasts derived from ATMF options; particularly BOI and OTC options outperform all other alternatives. However, all forecasts have over-estimated the realized future volatility during the sample period. These findings are relevant for policy making as well for investors in small open economies. Further research is needed to examine the factors that affect both the IVs and the B-A spreads where the same instrument trades in several markets simultaneously. 


\section{REFERENCES}

Amihud Y. (2002), "Illiquidity and stock returns: cross-section and time-series effects". Journal of Financial Markets, 5, pp. 31-56.

Amihud Y. and H. Mendelson (2006), "Stock and Bond Liquidity and its Effect on Prices and Financial Policies", Financial Markets Portfolio Management, 20, pp. 19-32.

Andersen T. G., Bollerslev T., Diebold F. X., and P. Labys (2001), “The Distribution of Realized Exchange Rate Volatility", Journal of American Statistical Association, 96, pp.42-55.

Black, F. (1976), "The pricing of commodity contracts", Journal of Financial Economics, 3, 167-179.

Bollen N.P.B., Gray S.F., and R.E. Whalely (2000), "Regime switching in foreign exchange rates: Evidence from currency option prices,” Journal of Econometrics, 94, pp. 239-276.

Brenner M., Eldor R. and S. Hauser (2001), "The Price of Options Illiquidity”, Journal of Finance, 56, pp. 789-805.

Campa J.M. and P.H.K. Chang (1995), "Testing the Expectations Hypothesis on the Term Structure of Volatilities in Foreign Exchange Options", Journal of Finance, 50, pp.529-47.

Carr P. and L. Wu (2004), "Stochastic Skew in Currency Options", Baruch College Working Paper, New York.

Christensen, B.J., and N.R. Prabhala (1998), "The Relation between Implied and Realized Volatility", Journal of Financial Economics 50, 1998, 125-150.

Deuskar, P., Gupta, A., and M. Subrahmanyam (2006), "Liquidity Effects in Interest Rate Options Markets: Premium or Discount?", New York University WP November.

Duan J.C. and J. Wei (1999), "Pricing Foreign Currency and Cross-Currency Options under GARCH", Journal of Derivatives, pp. 51-63.

Eldor R., Hauser S., Pilo B. and Shurki I. (2006), "The Contribution of Market Makers to Liquidity and Efficiency of Options Trading in Electronic Markets", Journal of Banking and Finance, Forthcoming.

Eldor R., Hauser S., Kahn M., and A. Kamara (2006), “The Contribution of Market Makers to Liquidity and Efficiency of Options Trading in Electronic Markets", Journal of Business, Forthcoming.

Garman, Mark B. and S.W. Kohlhagen (1983), "Foreign currency option values", Journal of International Money and Finance, 2, pp. 231-237. 
Glosten L.R., R. Jagannathan, and D.E. Runkle (1993), "On the relation between the expected value and volatility of the nominal excess return on stocks", Journal of Finance, 48, pp.1779-1801.

Goncalves S. and M. Guidolin (2006), "Predictable Dynamics in the S\&P500 Index Options Implied Volatility Surface", Journal of Business, Forthcoming.

Granger C. and S.H. Poon (2003), "Forecasting Volatility in Financial Markets: A Review", Journal of Economic Literature, Vol. XLI, pp. 478-539.

Jorion P. (1995), "Predicting Volatility in the Foreign Exchange market", Journal of Finance,50, pp.507-528.

Kim M. (2003), "Implied Volatility Dynamics in the Foreign Exchange Markets", Journal of International Money and Finance, Vol. 22, pp. 511-528.

Low B.S. and S. Zhang (2005), "The Volatility Risk Premium Embedded in Currency Options", Journal of Financial and Quantitative Analysis, Vol. 40, pp. 803-832.

Pong S., Shackleton M.B., Taylor S.J., and X. Xu (2004) "Forecasting currency volatility: A comparison of implied volatilities and AR(FI)MA models", Journal of Banking and Finance, 28 , pp. 2541-2563.

Szakmary A., Ors E., Kim J.K., and W.N. Davidson (2003), "The predictive power of implied volatility: Evidence from 35 markets", Journal of Banking and Finance, 2151-2175. 
Figure 1

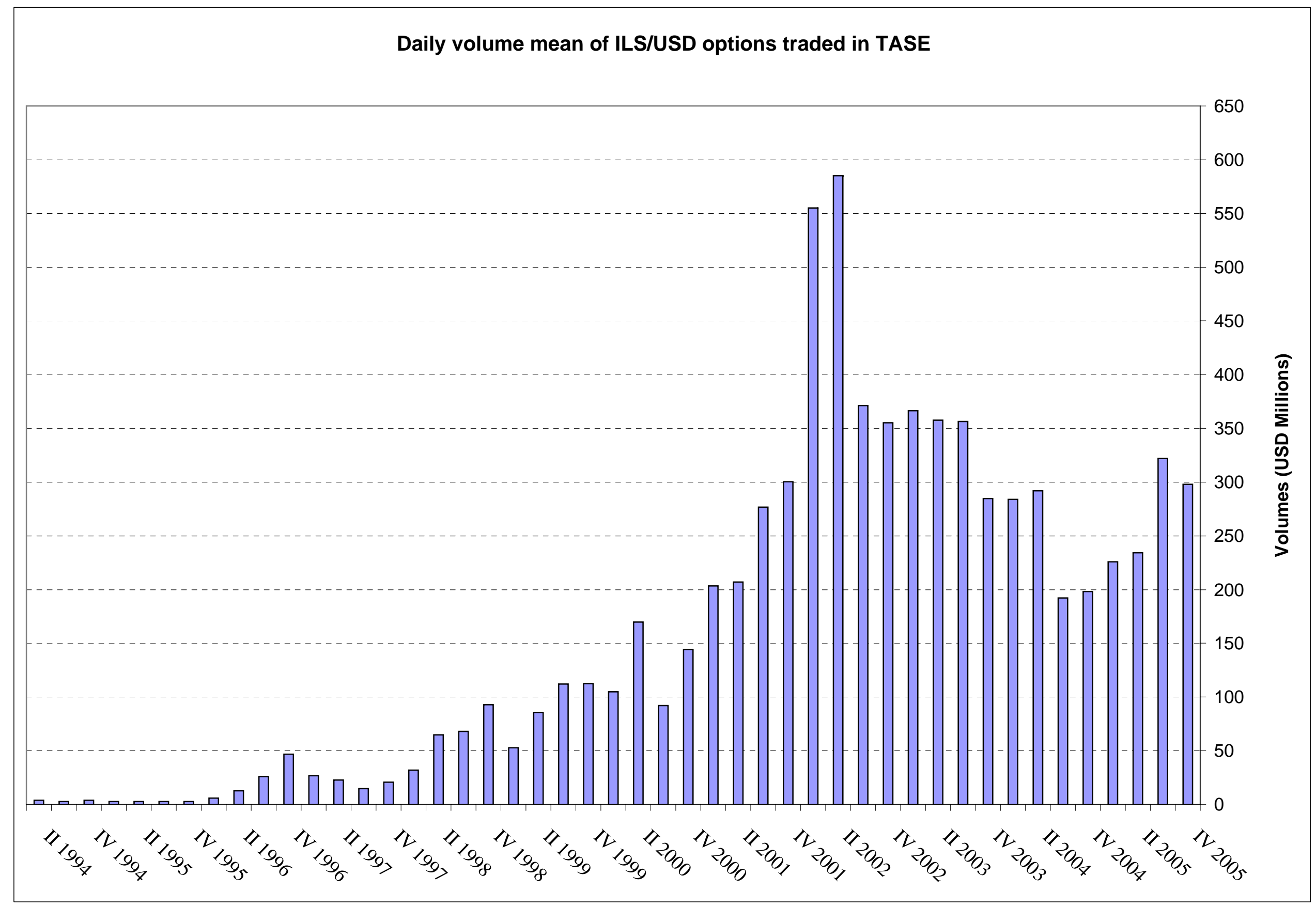


Figure 2

ILS/USD exchange rate and IV of BOI, OTC, and TASE, FX options

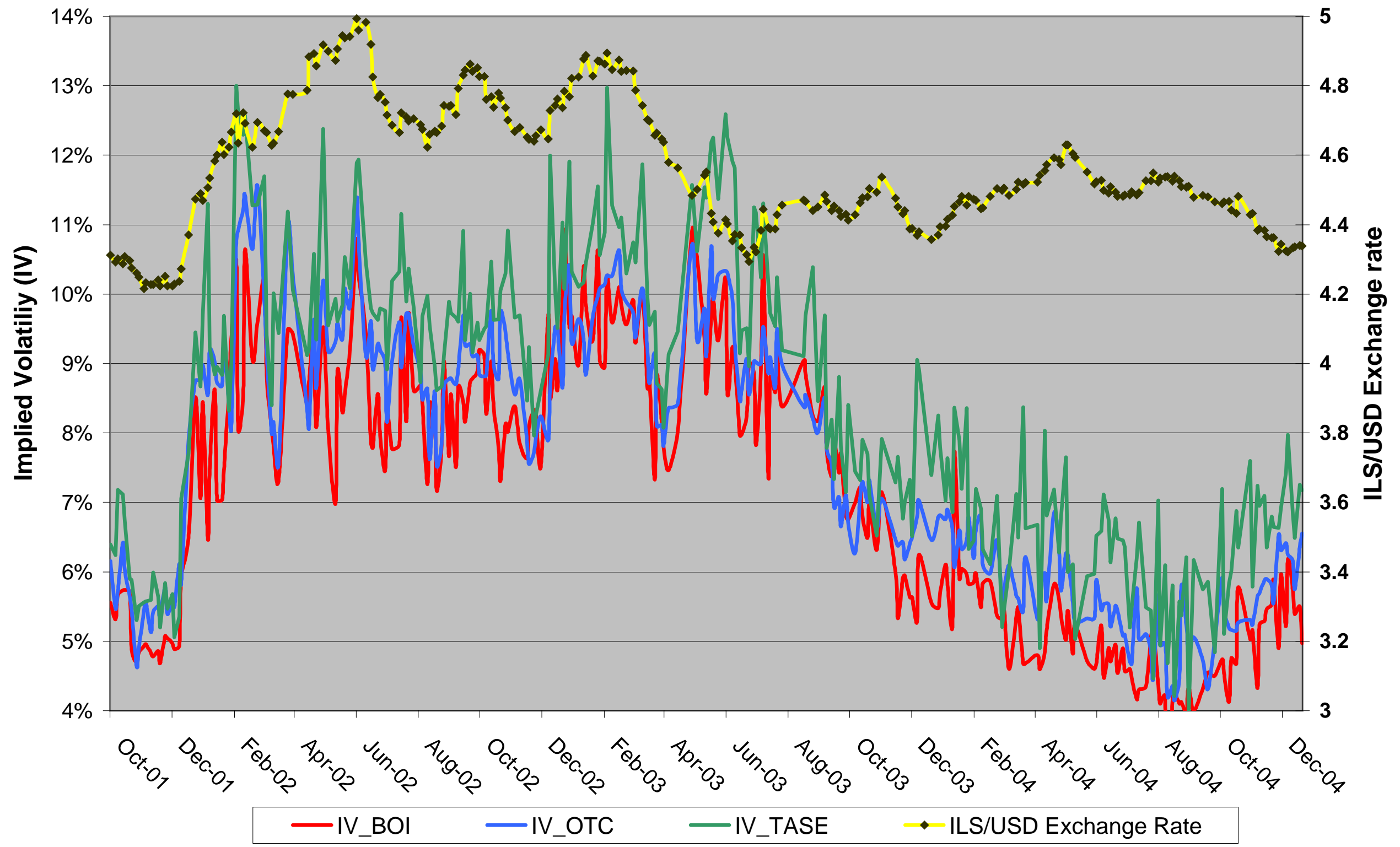

1) Daily means of all options and no filttering Days when all 3 markets were active 
Figure 3

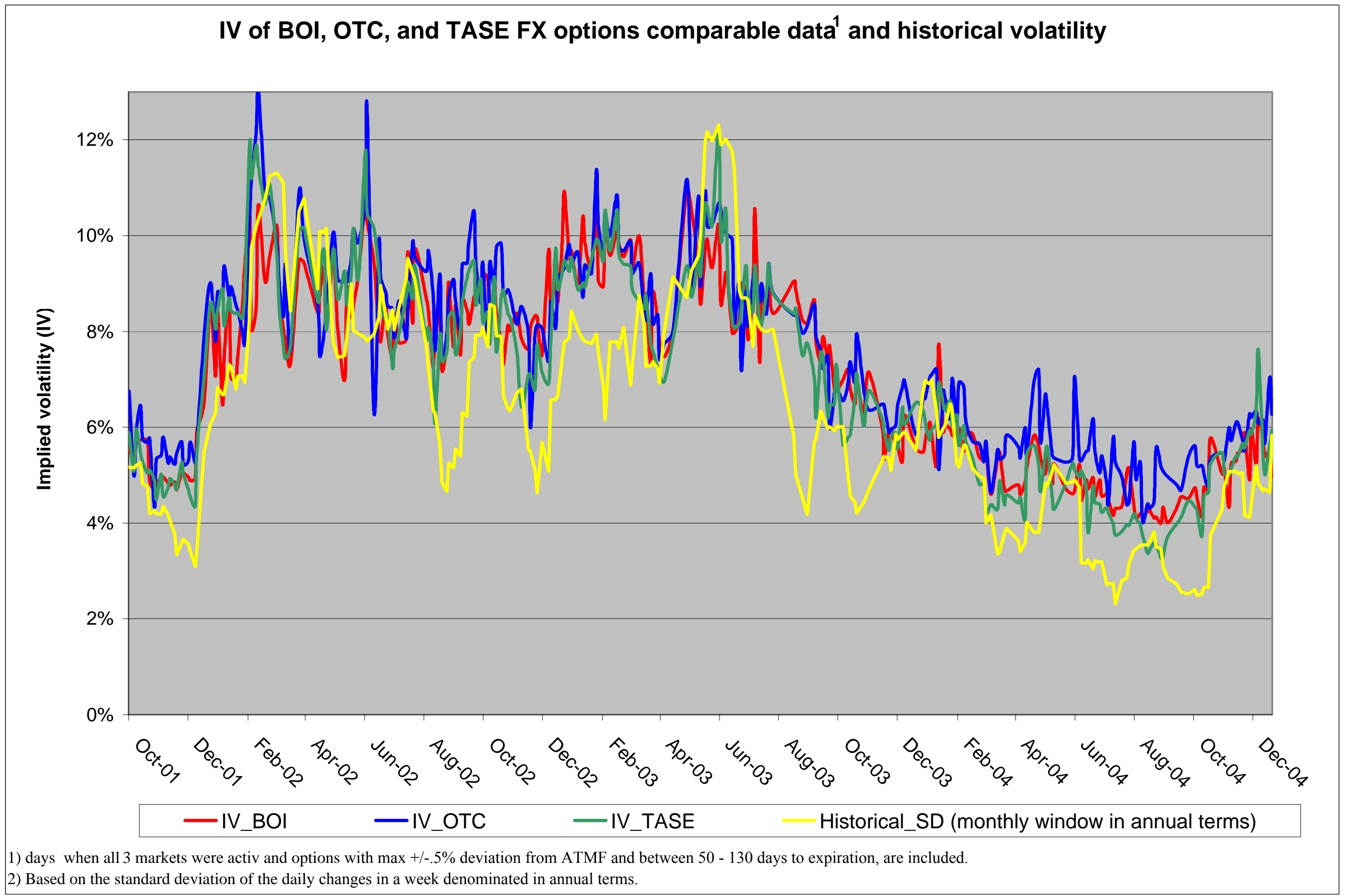




\section{Figure 4}

\section{BEH's liquidity premium surface: OTC vs. TASE}

\begin{tabular}{|l|}
\hline$\square 0.6-0.7$ \\
$\square 0.5-0.6$ \\
$\square 0.4-0.5$ \\
$\square 0.3-0.4$ \\
$\square 0.2-0.3$ \\
$\square 0.1-0.2$ \\
$\square 0-0.1$ \\
$\square-0.1-0$ \\
$\square-0.2--0.1$ \\
\hline
\end{tabular}

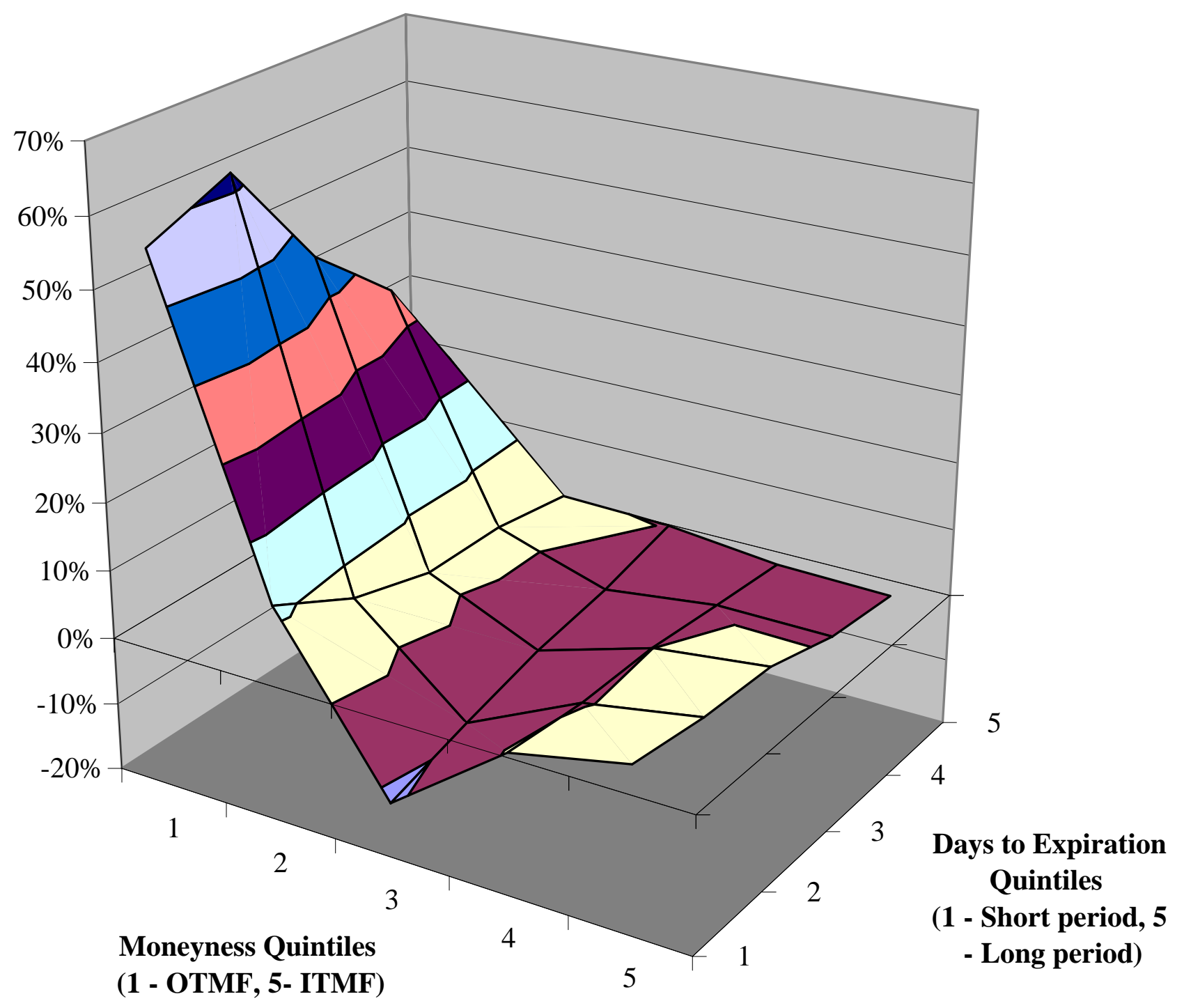

Based on method 1 of Brenner et al. (2001). Positive figures mean that TASE liquidity premium > OTC. Quintiles are presented in Table 3. 
Figure 5a

\section{Implied volatility surface of OTC options}

$\square 0.14-0.16$

$\square 0.12-0.14$

$\square 0.1-0.12$

$\square 0.08-0.1$

$\square 0.06-0.08$

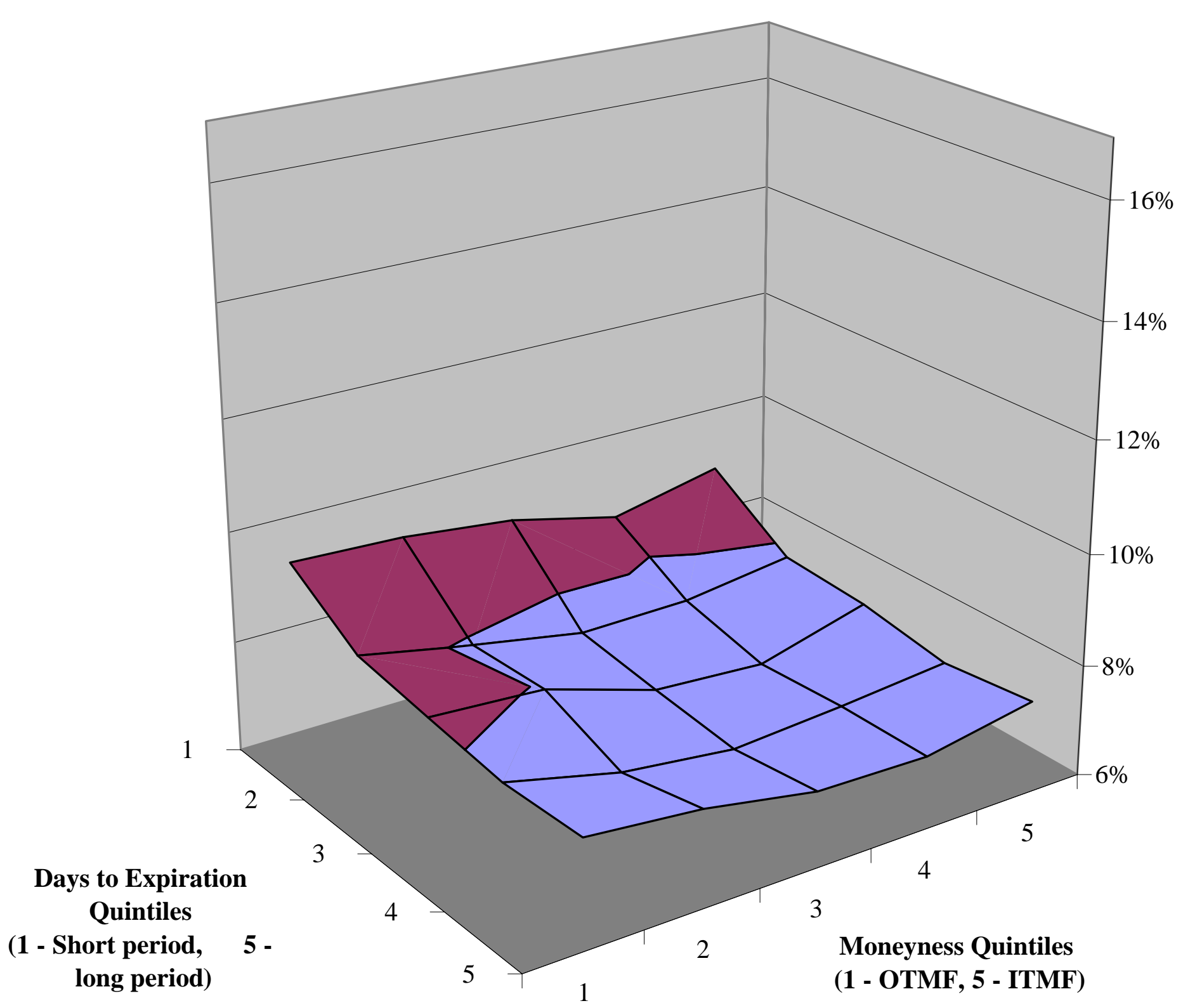

The surface reflects a 'flat' shape with a tendency of 'smirk'. For Moneyness and Days to Expiration quintiles, see the lower panel of Table 3. 


\section{Figure 5b}

\section{Implied volatility surface of TASE options}

0.14-0.16

$\square 0.12-0.14$

$\square 0.1-0.12$

$\square 0.08-0.1$

$\square 0.06-0.08$

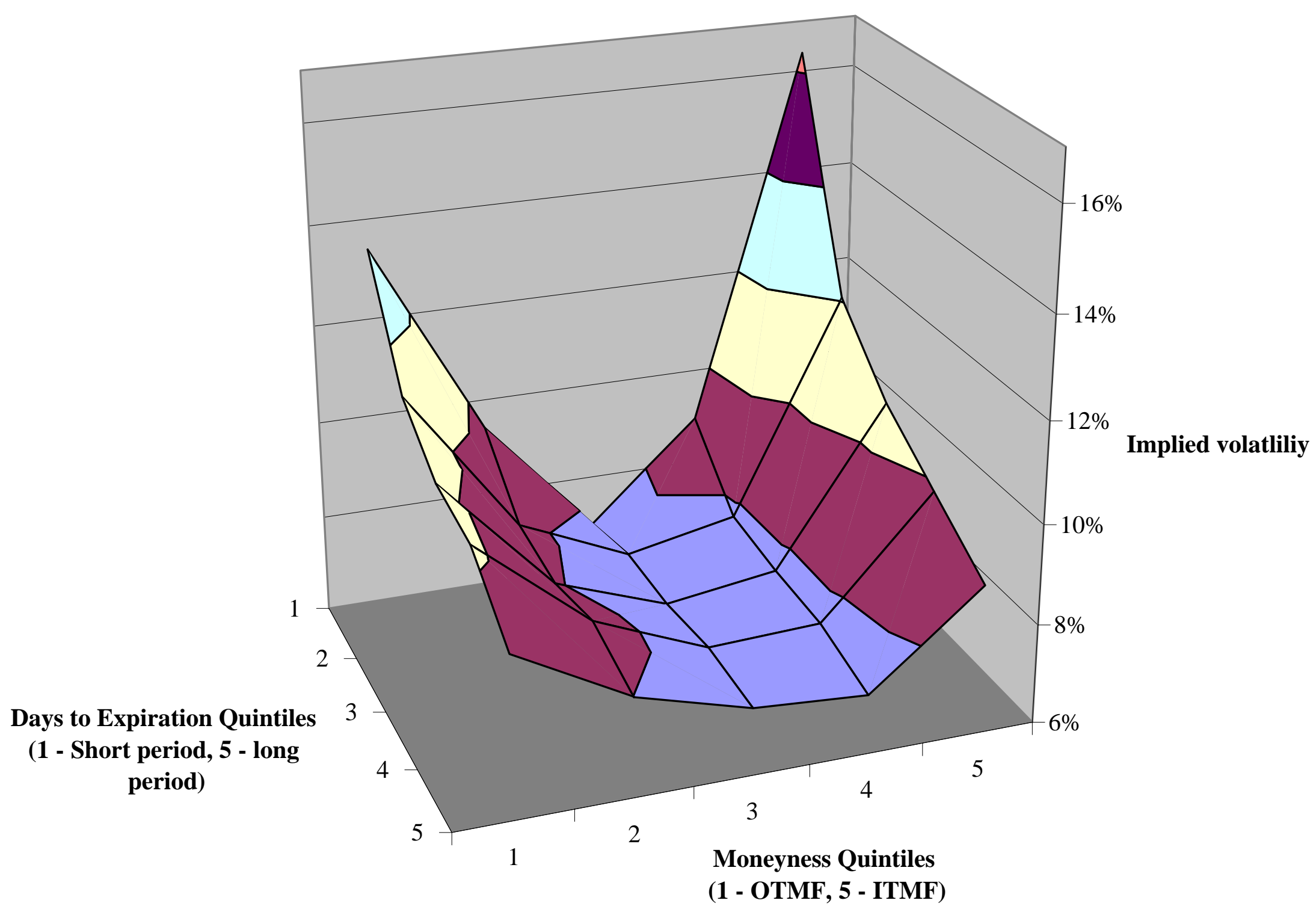

The surface reflects 'smile' shape For Moneyness and Days to Expiration quintiles, see the lower panel of Table3. 
A comparison between the forecasting ability of the $3 \mathrm{FX}$ option markets (comparabale quarterly data, 2002Q1 - 2005Q2)

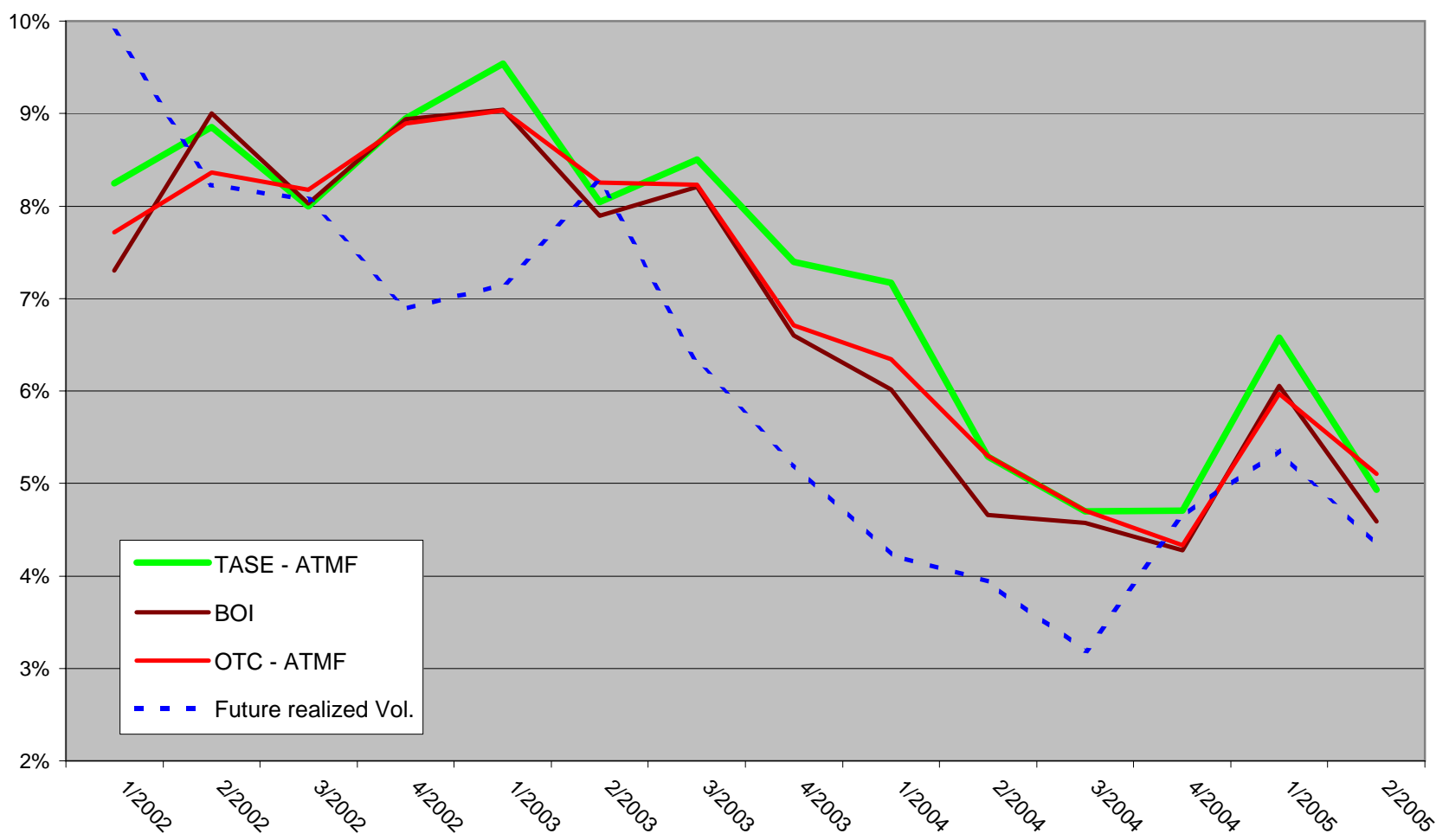

Correlation Coefficients Matrix

\begin{tabular}{|l|rr|r|r|}
\hline & TASE - ATMF & BOI & OTC - ATMF & Future volatility \\
\hline Future realized volatility $^{1}$ & 0.78 & 0.79 & 0.80 & 1 \\
OTC ATMF $^{2}$ options & 0.98 & 0.99 & 1 & 0.80 \\
BOI $^{2}$ options & 0.98 & 1 & 0.99 & 0.79 \\
TASE ATMF $^{2}$ options & 1 & 0.98 & 0.98 & 0.78 \\
\hline
\end{tabular}

\begin{tabular}{|l|ccccc|}
\hline & TASE - ATMF & TASE - ALL & BOI & OTC - ATMF & OTC - ALL \\
\hline $\mathbf{M E}^{3}$ & $-1.09 \%$ & $-1.34 \%$ & $-0.68 \%$ & $-0.82 \%$ & $-1.17 \%$ \\
RMSE $^{4}$ & $2.7 \%$ & $3.3 \%$ & $1.9 \%$ & $2.0 \%$ & $2.8 \%$ \\
Correlation coefficient & 0.78 & 0.78 & 0.79 & 0.80 & 0.79 \\
\hline
\end{tabular}

1) Calculated as the standard deviation of daily changes (\%) in ILS/USD exchange rate over the next quarter.

2) Derived from implied volatility of 3 months ATMF options traded in the first week of each quarter.

3) Reflects the direction of the biasness of the forecast from the future realized volatility [Avg (realized-IV)].

4) Measures the disperssion of the forcast around the future realized volatility [Avg (realized-IV) $\left.{ }^{2}\right]$. 


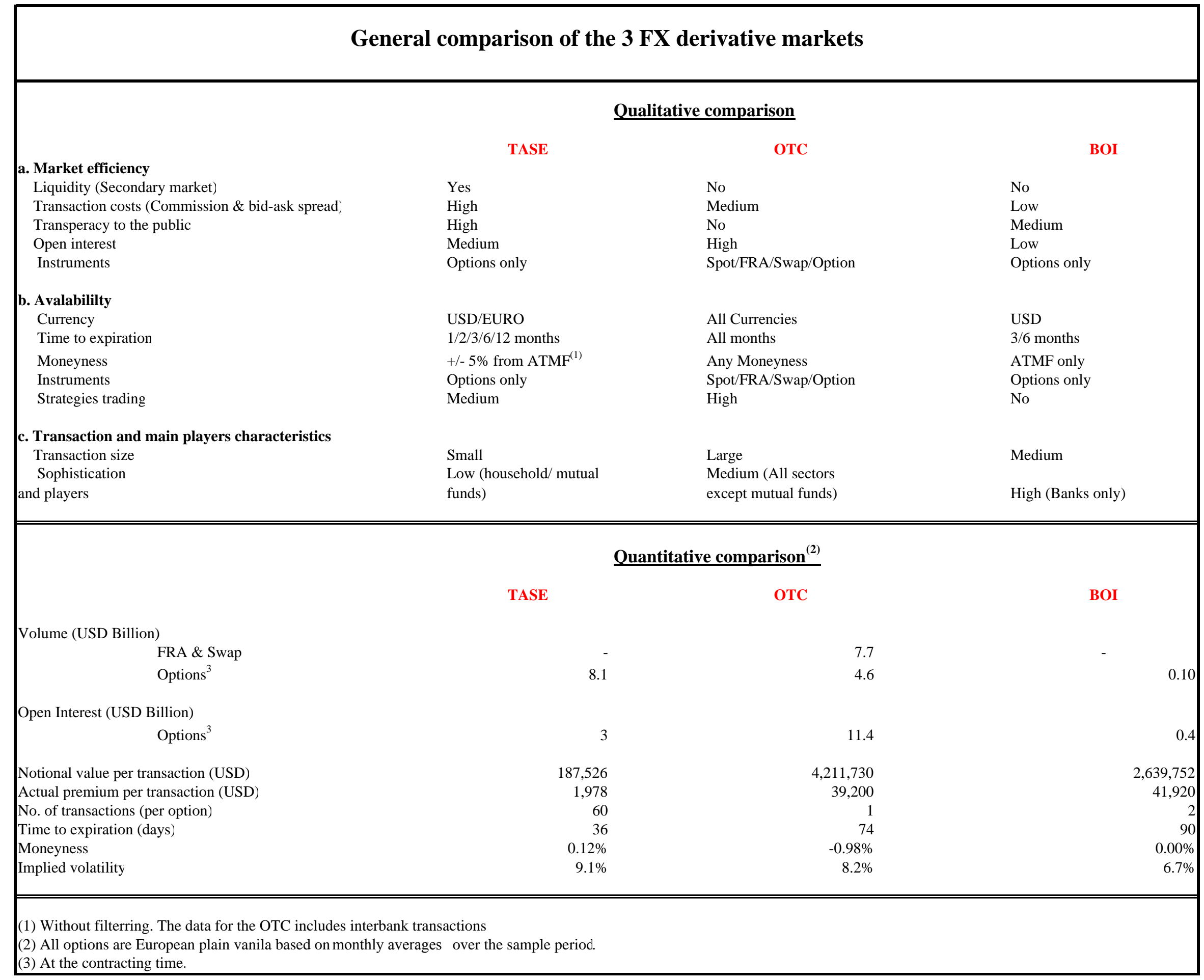


Table 2

The 3 FX option markets: Basic statistics

(Call and Put options, no filterring')

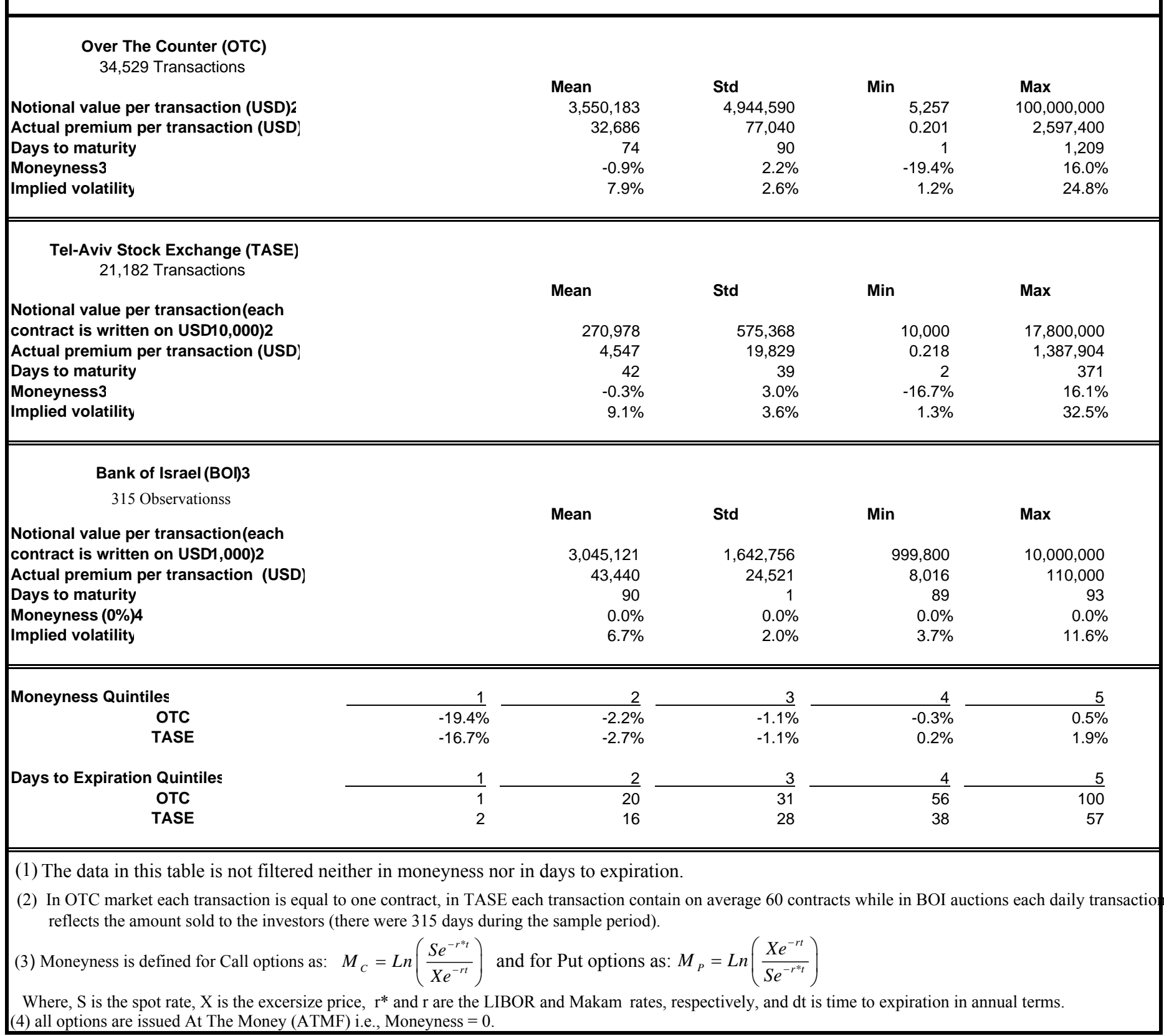


A comparison between OTC and TASE: Basic statistics by the type of option

(Call vs. Put options, no filterring')

Over The Counter (OTC)

Calls $(18,418$ transactions)

Notional value per transaction (USD) ${ }^{2}$

Actual premium per transaction (USD)

Days to maturity

Moneyness $^{3}$

Implied volatility

Puts (16,111 transactions)

Notional value per transaction (USD) ${ }^{2}$

Actual premium per transaction (USD)

Days to maturity

Moneyness $^{3}$

Implied volatility

\section{Mean}

$3,580,313$
32,633
76
$-0.6 \%$
$8.2 \%$

$3,515,739$

32,747

71

$-1.3 \%$

$7.5 \%$
Std

$5,044,077$

68,112

99
$2.1 \%$

$2.7 \%$

$4,828,273$
86,121
78
$2.2 \%$
$2.5 \%$

$4,828,273$

78

$2.5 \%$

Min

$$
\begin{array}{r}
5,257 \\
0.20 \\
1 \\
-16.9 \% \\
1.2 \%
\end{array}
$$

10,000

0.20

1
$-19.4 \%$

$1.3 \%$

\section{Tel-Aviv Stock Exchange (TASE)}

\section{Calls (12,435 transactions)}

Notional value per transaction (USD) ${ }^{2}$

Actual premium per transaction (USD)

Days to maturity

Moneyness $^{3}$

Implied volatility

Puts $(8,747$ transactions $)$

Notional value per transaction (USD) ${ }^{2}$

Actual premium per transaction (USD)

Days to maturity

Moneyness ${ }^{3}$

Implied volatility
Mean

264,036

5,128

46
$-0.2 \%$

$9.4 \%$

280,846

3,720

36

$-0.5 \%$

$8.7 \%$
Std

574,390

20,286

43

$3.2 \%$
$3.7 \%$

Min

10,000

0.22

$-16.7 \%$

$1.3 \%$

576,643

$\begin{array}{r}19,133 \\ \hline\end{array}$

33

$2.6 \%$

$3.5 \%$
$\operatorname{Max}$

$100,000,000$ $2,002,000$

1,209

$16.0 \%$

$19.7 \%$

$75,350,000$

$2,597,400$

734

$8.5 \%$

$24.8 \%$

(1) The data in this table is not filtered neither in moneyness nor in days to expiration.

(2) In OTC market each transaction is equal to one contract, in TASE each transaction contain on average 60 contracts while in BOI auctions each daily transaction

reflects the amount sold to the investors (there were 315 days during the sample period).

(3) Moneyness is defined for Call options as: $M_{C}=\operatorname{Ln}\left(\frac{S e^{-r * t}}{X e^{-r t}}\right)$ and for Put options as: $M_{P}=\operatorname{Ln}\left(\frac{X e^{-r t}}{S e^{-r * t}}\right)$

Where, $\mathrm{S}$ is the spot rate, $\mathrm{X}$ is the excersize price, $\mathrm{r}^{*}$ and $\mathrm{r}$ are the LIBOR and Makam rates, respectively, and $\mathrm{dt}$ is time to expiration in annual terms. 
ILS/USD exchange rate changes (\%) - data generating process and basic statistics

(daily changes for the sample period: 10/2001 - 12/2004)

Dependent Variable $\left(Y_{t}\right)$ : ILS/USD changes (\%)

$\operatorname{GARCH}(1,1)$

1. Mean equetion: $Y_{t}=\lambda+\varepsilon_{t}$

2. Variance equetion: $\sigma_{t}^{2}=\omega+\alpha \varepsilon_{t-1}^{2}+\beta \sigma_{t-1}^{2}$ Coefficient Std. Error z-Statistic Prob.

$\begin{array}{lrrrr}\lambda & 0.00 & 0.00 & -0.59 & 0.56 \\ \omega & 0.00 & 0.00 & 2.53 & 0.01 \\ \alpha & 0.05 & 0.01 & 4.68 & 0.00 \\ \beta & 0.95 & 0.01 & 95.65 & 0.00\end{array}$

Threshold GARCH - TARCH $(1,1)^{1}$

1. Mean equetion : $Y_{t}=\lambda+\varepsilon_{t}$

2. Variance equetion : $\sigma_{t}^{2}=\omega+\alpha \varepsilon_{t-1}^{2}+\beta \sigma_{t-1}^{2}+\gamma \varepsilon_{t-1}^{2} \Gamma_{t-1}$ where, $\Gamma_{t}=1$ if $\varepsilon_{t-1}<0$.

Coefficient Std. Error z-Statistic Prob.

$\begin{array}{lrrrr}\lambda & 0.00 & 0.00 & -0.38 & 0.70 \\ \omega & & & & \\ \alpha & 0.00 & 0.00 & 2.70 & 0.01 \\ \gamma & 0.07 & 0.01 & 4.72 & 0.00 \\ \beta & -0.03 & 0.01 & -2.21 & 0.03 \\ & 0.94 & 0.01 & 99.54 & 0.00\end{array}$

Exponential GARCH - EGARCH(1,1 $)^{2}$

1. Mean equetion $Y_{t}=\lambda+\varepsilon_{t}$

2. Variance equetion $\log \left(\sigma_{t}^{2}\right)=\omega+\alpha \log \left(\sigma_{t-1}^{2}\right)+\beta\left|\frac{\varepsilon_{t-1}}{\sigma_{t-1}}\right|+\gamma \frac{\varepsilon_{t-1}}{\sigma_{t-1}}$

Coefficient Std. Error z-Statistic Prob.

$\begin{array}{lrrrr} & & & & \\ \lambda & 0.00 & 0.00 & -0.48 & 0.63 \\ \omega & -0.20 & 0.04 & -4.98 & 0.00 \\ \alpha & 0.12 & 0.02 & 5.90 & 0.00 \\ \gamma & 0.03 & 0.01 & 2.74 & 0.01 \\ \beta & 0.99 & 0.00 & 291.75 & 0.00\end{array}$

See Glosten, Jaganathan, and Runkle (1993)

See Nelson (1991).

Unit root tests. All results indicate that there is no unit root at the $1 \%$ confidence level.

4) The normal distributed line is simulated using the mean and the variance of the ILS/USD exchange rate changes during the sample period.

Basic statistics

Mean

Median

Minimum

Std. Deviation

Skewnes

Jarque-Bera test

for normality

Probability
$-0.0014 \%$

$0.00 \%$

$2.39 \%$
$-2.15 \%$

$0.4305 \%$

0.10

2.96

15.25

Augumented Dickey Fuller (ADF) test ${ }^{3}$

(Maximum Lag length $=10$ )

None
Constan t only

Constant and Tren

$-7.2$

$-7.3$

Phillips Perron (PP) test

None (Barttlet Kernel)

$\begin{array}{ll} & -13.59 \\ \text { Constant only } & -13.55\end{array}$

$\begin{array}{ll}\text { Constant and Trend } & -13.57\end{array}$

Histogram of ILS/USD exchange rate changes (\%) vs. Normal distribution ${ }^{4}$

00

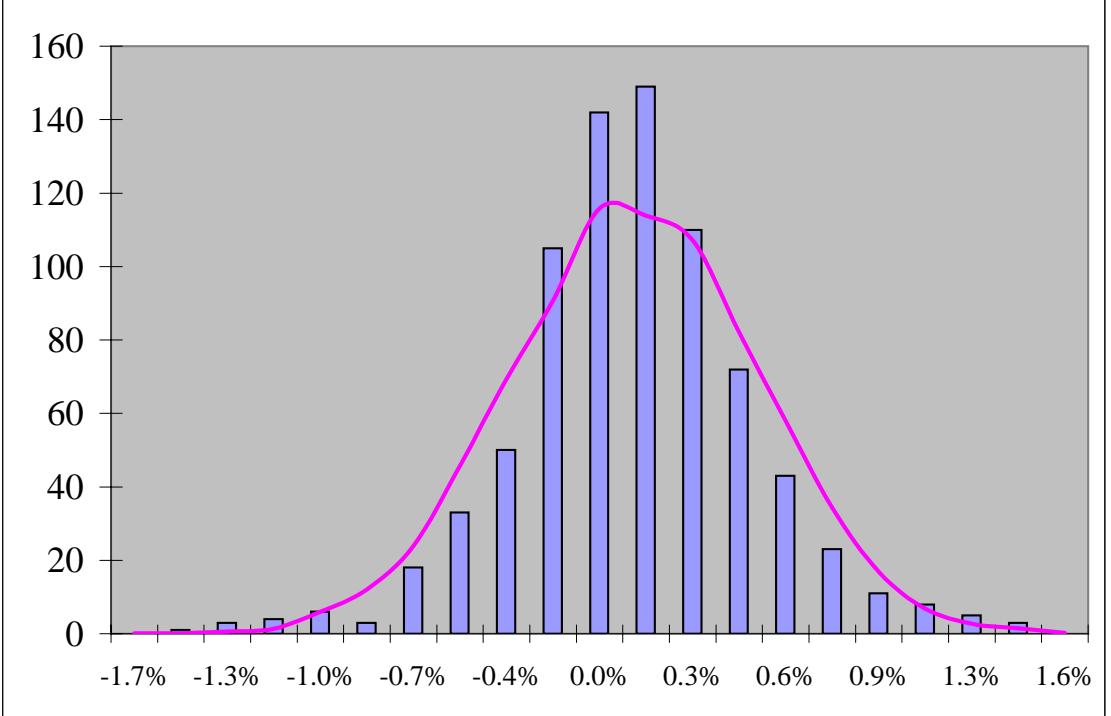


Table 5

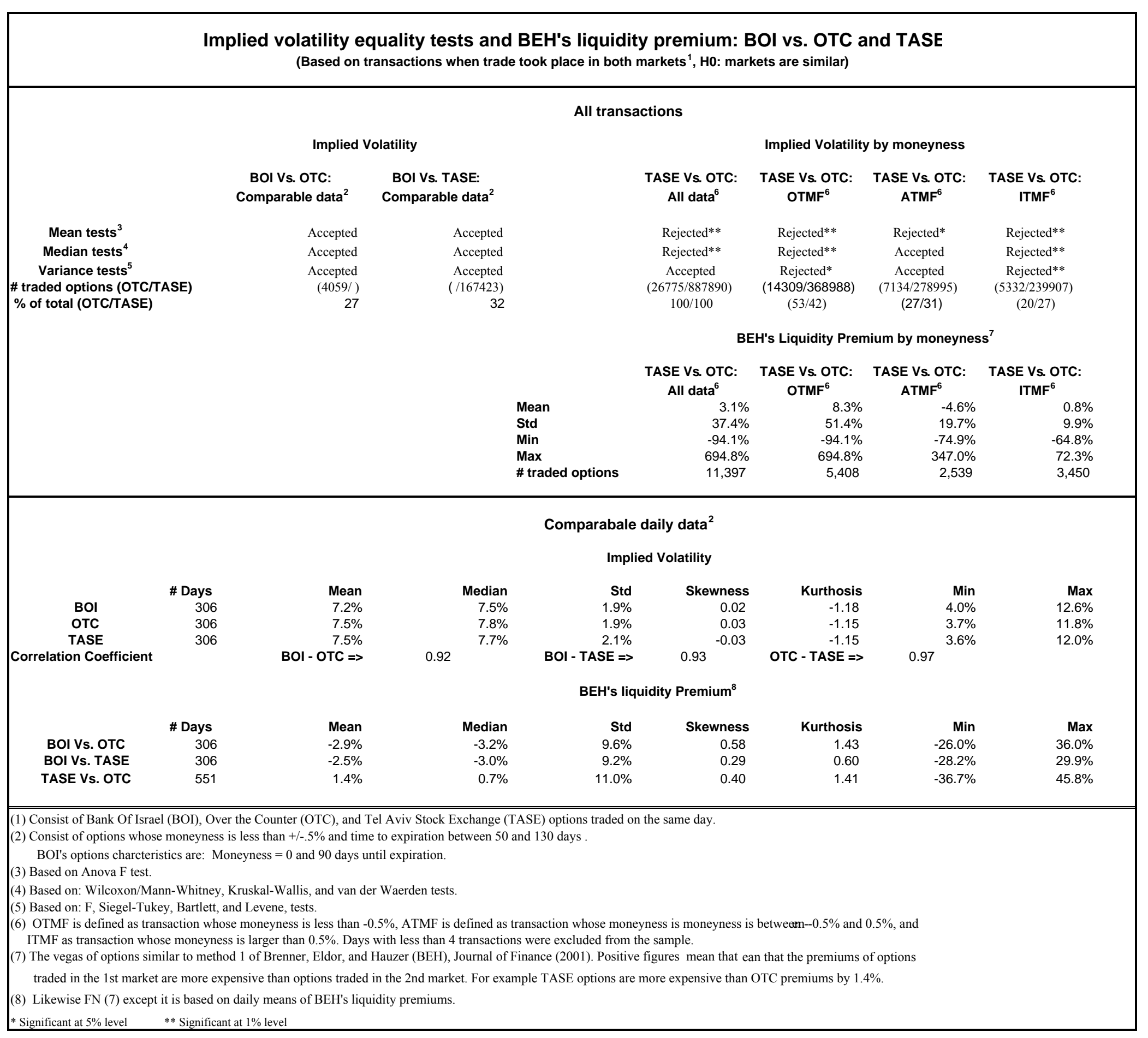




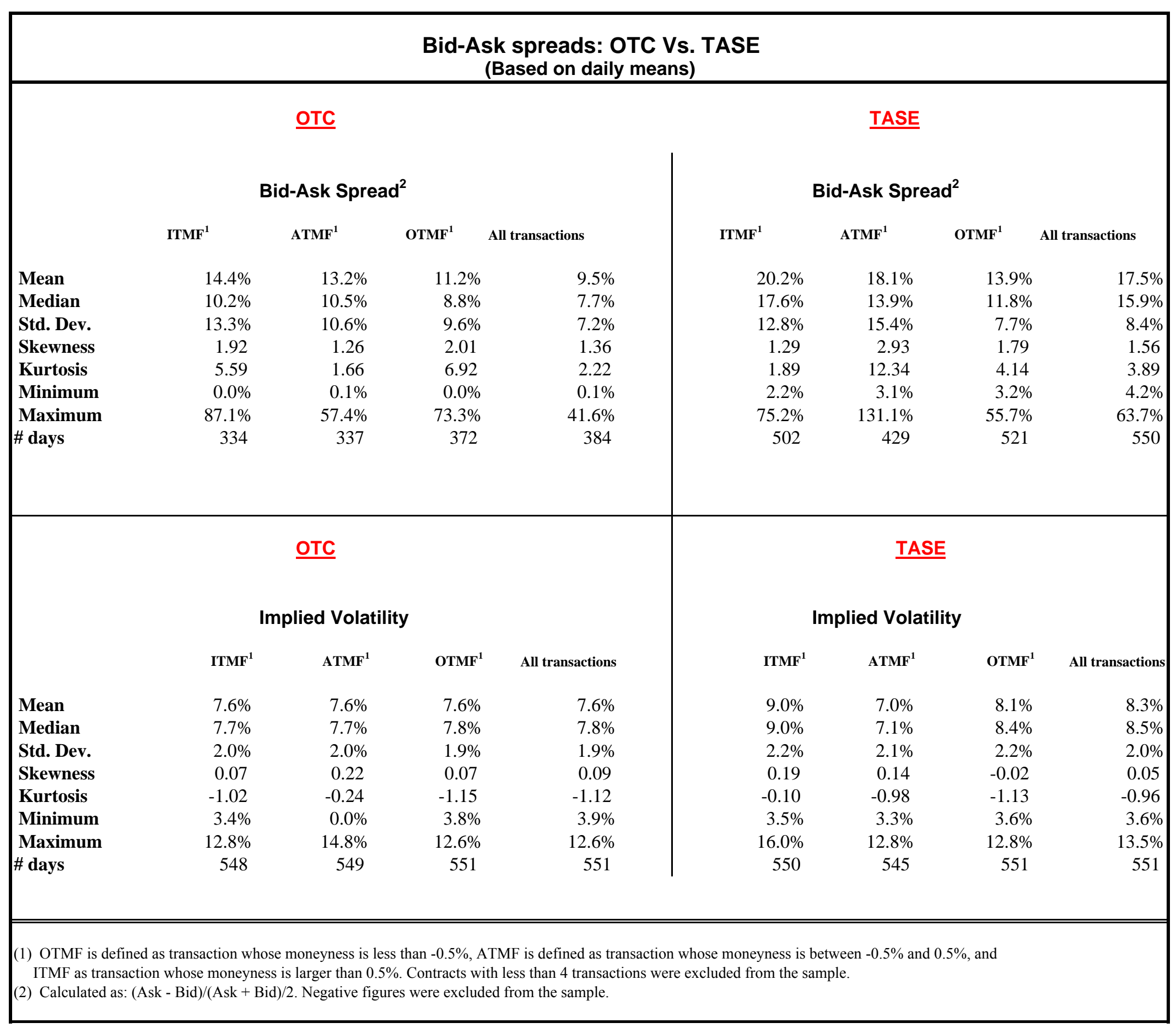


OLS and TSLS Regression results of the changes in Bid-ask spreads and Implied Volatility: OTC Vs. TASE (Based on means of 551 days where both markets were active)

\begin{tabular}{|c|c|c|c|c|c|c|}
\hline \multirow[t]{2}{*}{ a) OLS: Endogenous variable: } & \multicolumn{3}{|c|}{$\frac{\underline{\text { TASE }}}{\Delta \text { Bid-Ask Spread }}$} & \multicolumn{3}{|c|}{$\begin{array}{l}\underline{\text { OTC }} \\
\Delta \text { Bid-Ask Spread }\end{array}$} \\
\hline & Coefficient & t-statistic & Prob. $^{1}$ & Coefficient & t-statistic & Prob. $^{1}$ \\
\hline Intercept & -0.47 & -0.13 & 0.90 & 42.12 & 2.62 & 0.01 \\
\hline$\Delta$ Implied volatility & 2.01 & 4.97 & 0.00 & 2.44 & 1.84 & 0.07 \\
\hline Log(Notional Value) & 0.03 & 0.14 & 0.89 & -2.23 & -2.61 & 0.01 \\
\hline$\Delta$ Days to expiration & 0.04 & 1.12 & 0.26 & 0.00 & -0.05 & 0.96 \\
\hline$\Delta$ Moneyness & -1.19 & -1.81 & 0.07 & -2.66 & -1.42 & 0.16 \\
\hline $\operatorname{AR}(8) / A R(3)^{2}$ & -0.49 & -8.62 & 0.00 & -0.52 & -5.79 & 0.00 \\
\hline $\begin{array}{l}\text { Adjusted } \mathrm{R}^{2} \\
\text { D.W. }\end{array}$ & & $\begin{array}{l}0.45 \\
1.99 \\
\end{array}$ & & & $\begin{array}{l}0.45 \\
2.00 \\
\end{array}$ & \\
\hline \multirow[t]{2}{*}{ b) OLS: Endgenous variable: } & \multicolumn{3}{|c|}{$\Delta$ Implied Volatility } & \multicolumn{3}{|c|}{$\Delta$ Implied Volatility } \\
\hline & Coefficient & t-statistic & Prob. ${ }^{1}$ & Coefficient & t-statistic & Prob. $^{1}$ \\
\hline Intercept & -1.02 & -1.86 & 0.06 & -2.65 & -1.96 & 0.05 \\
\hline$\Delta$ Bid-Ask Spread & 0.02 & 4.62 & 0.00 & 0.01 & 1.75 & 0.08 \\
\hline Log(Notional Value) & 0.07 & 1.86 & 0.06 & 0.14 & 1.98 & 0.05 \\
\hline$\Delta$ Days to expiration & -0.01 & -3.53 & 0.00 & -0.01 & -2.89 & 0.00 \\
\hline$\Delta$ Moneyness & 0.36 & 6.23 & 0.00 & -0.20 & -2.09 & 0.04 \\
\hline $\operatorname{AR}(4) / A R(2)^{2}$ & -0.28 & -6.04 & 0.02 & -0.20 & -2.05 & 0.28 \\
\hline Adjusted $\mathbf{R}^{2}$ & & 0.34 & & & 0.14 & \\
\hline D.W. & & 2.00 & & & 1.97 & \\
\hline \multirow[t]{2}{*}{ c1) TSLS: Endgenous variable: } & \multicolumn{3}{|c|}{$\Delta$ Bid-Ask Spread } & \multicolumn{3}{|c|}{$\Delta$ Bid-Ask Spread } \\
\hline & Coefficient & t-statistic & Prob. ${ }^{1}$ & Coefficient & t-statistic & Prob. $^{1}$ \\
\hline Intercept & 0.88 & 0.21 & 0.83 & 43.29 & 2.78 & 0.01 \\
\hline$\Delta$ Implied volatility & 3.79 & 8.85 & 0.00 & 2.87 & 2.24 & 0.03 \\
\hline Log(Notional Value) & -0.05 & -0.20 & 0.84 & -2.29 & -2.78 & 0.01 \\
\hline$\Delta$ Days to expiration & 0.07 & 1.90 & 0.06 & 0.00 & 0.01 & 0.99 \\
\hline$\Delta$ Moneyness & -1.82 & -2.74 & 0.01 & -2.61 & -1.45 & 0.15 \\
\hline $\operatorname{AR}(6) / A R(3)^{2}$ & -0.45 & -8.74 & 0.00 & -0.51 & -5.97 & 0.00 \\
\hline Adjusted R ${ }^{2}$ & & 0.41 & & & 0.45 & \\
\hline D.W. & & 2.03 & & & 2.00 & \\
\hline \multirow[t]{2}{*}{ c2) TSLS: Endgenous variable: } & \multicolumn{3}{|c|}{$\Delta$ Implied Volatility } & \multicolumn{3}{|c|}{$\Delta$ Implied Volatility } \\
\hline & Coefficient & t-statistic & Prob. ${ }^{1}$ & Coefficient & t-statistic & Prob. $^{1}$ \\
\hline Intercept & -1.04 & -1.91 & 0.06 & -2.27 & -1.98 & 0.05 \\
\hline$\Delta$ Bid-Ask Spread & 0.03 & 8.52 & 0.00 & 0.01 & 1.96 & 0.05 \\
\hline Log(Notional Value) & 0.07 & 1.91 & 0.06 & 0.12 & 2.00 & 0.05 \\
\hline$\Delta$ Days to expiration & -0.01 & -3.66 & 0.00 & -0.01 & -3.25 & 0.00 \\
\hline$\Delta$ Moneyness & 0.36 & 6.31 & 0.00 & -0.15 & -2.09 & 0.04 \\
\hline $\operatorname{AR}(4) / \operatorname{AR}(1)^{2}$ & -0.30 & -6.66 & 0.01 & -0.28 & -4.01 & 0.00 \\
\hline Adjusted $\mathbf{R}^{2}$ & & 0.32 & & & 0.14 & \\
\hline D.W. & & 2.00 & & & 2.01 & \\
\hline
\end{tabular}




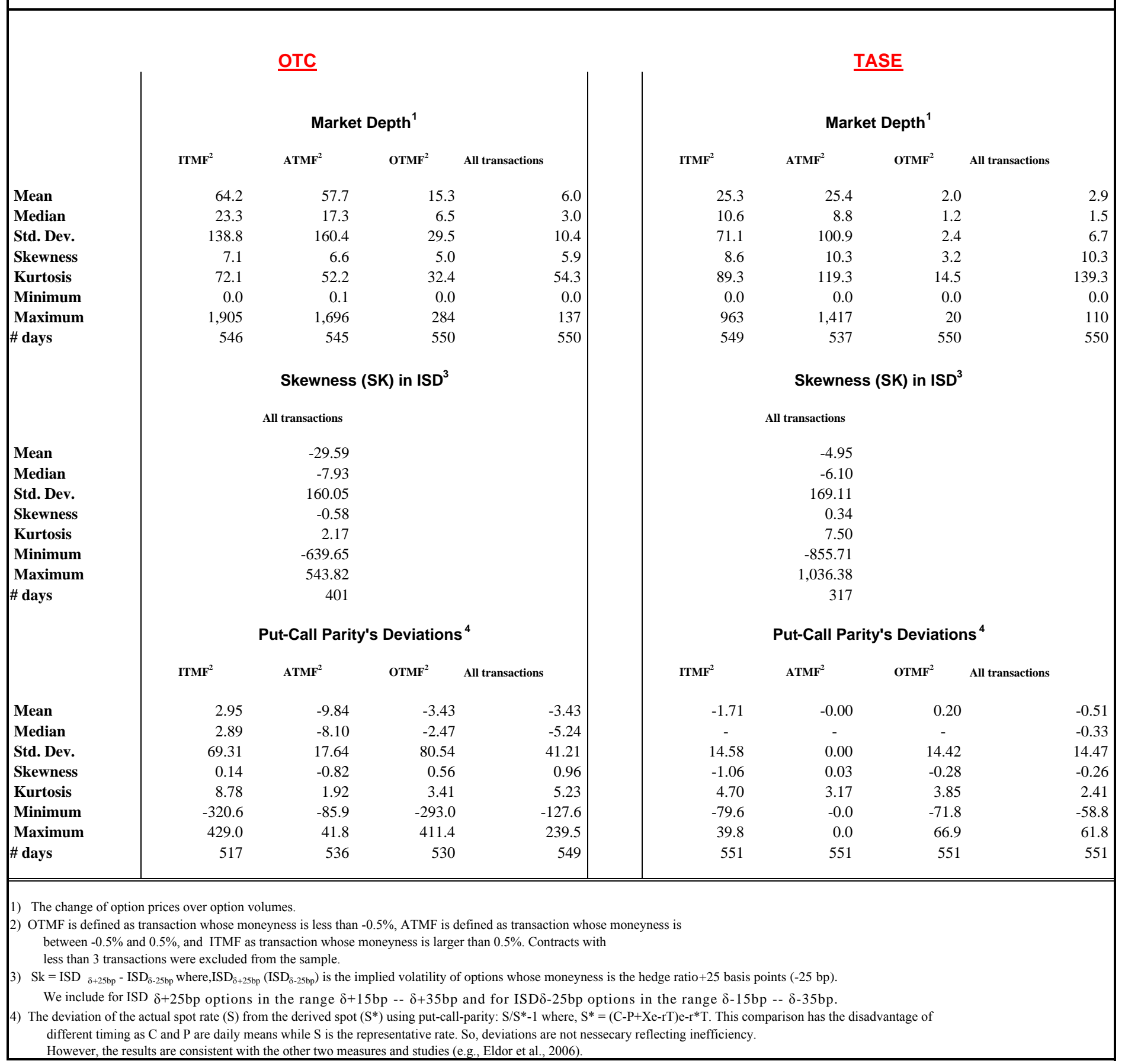


Table 9

\begin{tabular}{|c|c|c|c|c|c|c|c|c|c|}
\hline \multicolumn{10}{|c|}{$\begin{array}{r}\text { Number of transactions and volume of all options in OTC, TASE, and BOI around TASE's expiration day } \\
\text { (As percentage of TASE expiration day's data) }\end{array}$} \\
\hline \multirow[b]{2}{*}{ Day of the Month } & \multicolumn{3}{|c|}{ TASE } & \multicolumn{3}{|c|}{ OTC } & \multicolumn{3}{|c|}{ BOI } \\
\hline & Volume & Volume per & $\begin{array}{l}\text { Number of } \\
\text { transactions }\end{array}$ & Volume & Volume per & $\begin{array}{l}\text { Number of } \\
\text { transactions }\end{array}$ & Volume & Volume per & $\begin{array}{l}\text { Number of } \\
\text { transactions }\end{array}$ \\
\hline 1 & 28 & 41 & 69 & 48 & 103 & 46 & 20 & 82 & 25 \\
\hline 2 & 30 & 39 & 79 & 50 & 97 & 52 & 23 & 82 & 29 \\
\hline 3 & 35 & 43 & 82 & 55 & 99 & 56 & 37 & 110 & 34 \\
\hline 4 & 36 & 44 & 82 & 46 & 91 & 51 & 33 & 93 & 36 \\
\hline 5 & 29 & 43 & 68 & 50 & 103 & 49 & 36 & 118 & 30 \\
\hline 6 & 33 & 45 & 74 & 49 & 102 & 48 & 32 & 95 & 34 \\
\hline 7 & 32 & 47 & 69 & 42 & 84 & 50 & 23 & 105 & 21 \\
\hline 8 & 32 & 40 & 79 & 41 & 94 & 44 & 31 & 88 & 36 \\
\hline 9 & 40 & 44 & 90 & 53 & 104 & 51 & 25 & 86 & 29 \\
\hline 10 & 40 & 43 & 95 & 53 & 93 & 56 & 37 & 102 & 36 \\
\hline 11 & 41 & 46 & 89 & 61 & 93 & 66 & 38 & 96 & 39 \\
\hline 12 & 33 & 40 & 83 & 49 & 97 & 50 & 32 & 100 & 32 \\
\hline 13 & 40 & 46 & 87 & 47 & 98 & 47 & 35 & 89 & 39 \\
\hline 14 & 36 & 43 & 84 & 42 & 97 & 43 & 28 & 114 & 25 \\
\hline 15 & 36 & 45 & 80 & 45 & 95 & 47 & 34 & 105 & 32 \\
\hline 16 & 32 & 41 & 78 & 44 & 98 & 44 & 28 & 97 & 29 \\
\hline 17 & 53 & 58 & 92 & 51 & 94 & 54 & 30 & 94 & 32 \\
\hline 18 & 59 & 65 & 91 & 47 & 103 & 45 & 27 & 85 & 32 \\
\hline 19 & 72 & 77 & 93 & 63 & 110 & 57 & 34 & 112 & 30 \\
\hline 20 & 68 & 72 & 94 & 53 & 96 & 55 & 38 & 96 & 39 \\
\hline 21 & 53 & 64 & 83 & 37 & 87 & 43 & 26 & 105 & 25 \\
\hline 22 & 52 & 68 & 76 & 41 & 99 & 41 & 27 & 85 & 32 \\
\hline 23 & 47 & 81 & 57 & 22 & 83 & 27 & 23 & 108 & 21 \\
\hline 24 & 28 & 64 & 44 & 25 & 119 & 21 & 17 & 93 & 18 \\
\hline 25 & 20 & 69 & 29 & 22 & 122 & 18 & 16 & 87 & 18 \\
\hline 26 & 17 & 68 & 24 & 18 & 97 & 19 & 15 & 102 & 14 \\
\hline 27 & 23 & 64 & 36 & 23 & 101 & 22 & 25 & 138 & 18 \\
\hline 28 & 17 & 59 & 28 & 17 & 95 & 18 & 18 & 165 & 11 \\
\hline 29 & 16 & 46 & 36 & 20 & 81 & 24 & 18 & 98 & 18 \\
\hline 30 & 25 & 57 & 44 & 28 & 94 & 30 & 17 & 97 & 18 \\
\hline 31 & 20 & 74 & 27 & 27 & 111 & 24 & 17 & 117 & 14 \\
\hline Daily mean & 36 & 54 & 69 & 41 & 98 & 42 & 27 & 101 & 27 \\
\hline Day after expiration & 58 & 58 & 100 & 92 & 99 & 93 & 86 & 90 & 96 \\
\hline Day before expiration & 97 & 78 & 124 & 61 & 96 & 63 & 94 & 96 & 98 \\
\hline Expiration day ${ }^{2}$ & 100 & 100 & 100 & 100 & 100 & 100 & 100 & 100 & 100 \\
\hline
\end{tabular}




\section{Sensitivity of implied volatility to the Intraday USD Rate Used ${ }^{(1)}$}

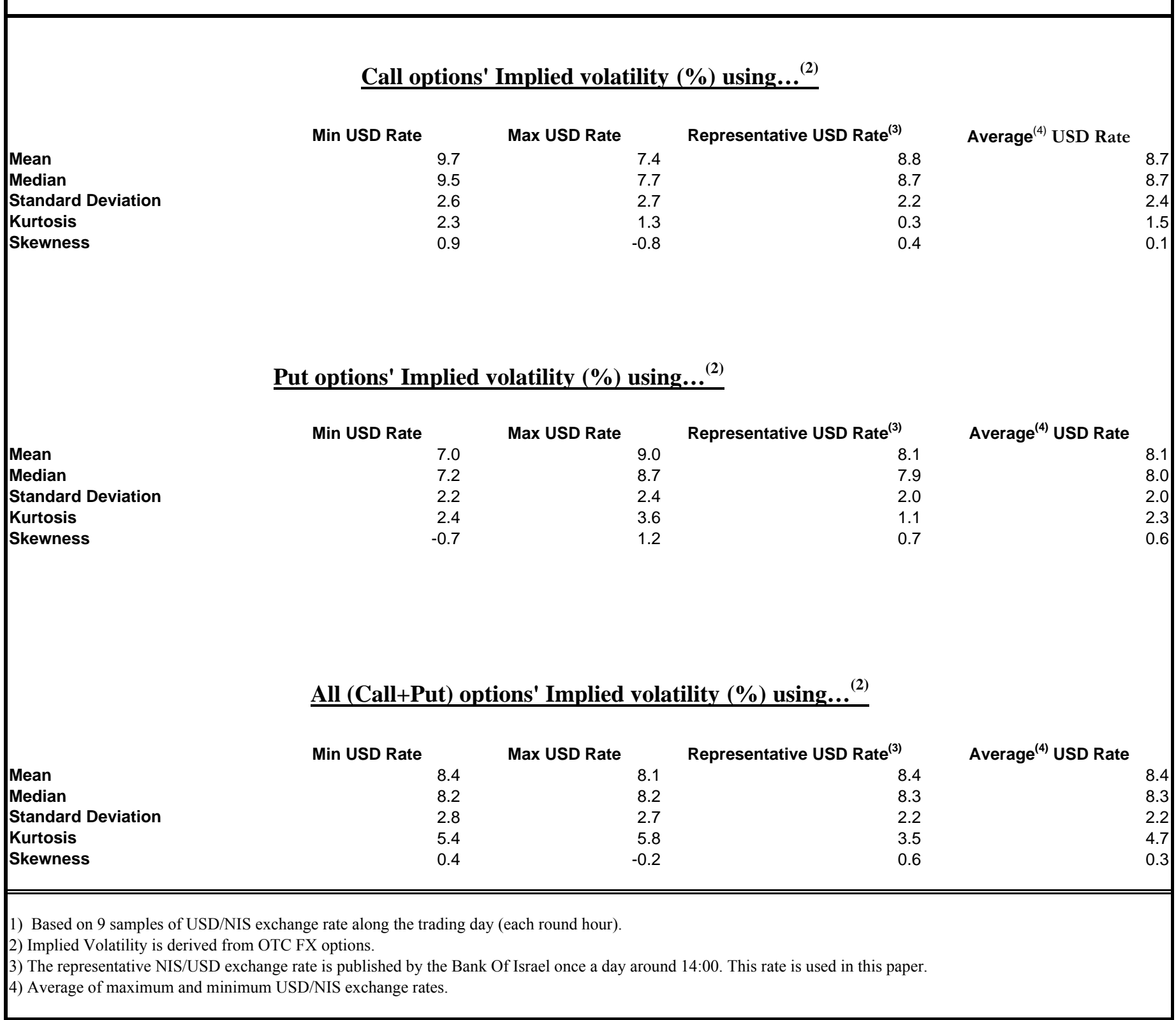

